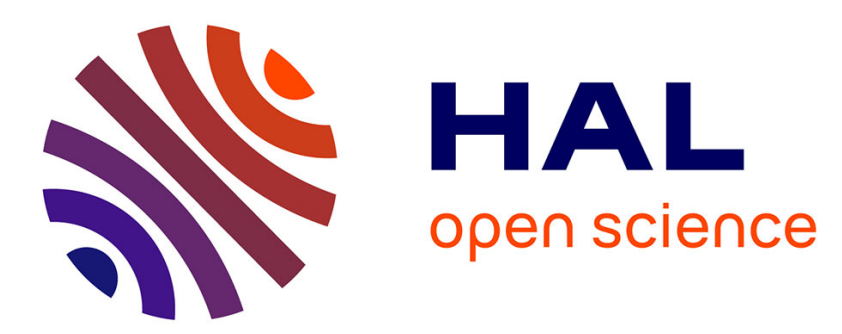

\title{
Robustness of SST teleconnections and precursory patterns associated with the Indian summer monsoon
}

Ghyslaine Boschat, Pascal Terray, Sébastien Masson

\section{To cite this version:}

Ghyslaine Boschat, Pascal Terray, Sébastien Masson. Robustness of SST teleconnections and precursory patterns associated with the Indian summer monsoon. Climate Dynamics, 2012, 38, pp.2143-2165. 10.1007/S00382-011-1100-7 . hal-00758318

\section{HAL Id: hal-00758318 https://hal.science/hal-00758318}

Submitted on 29 May 2016

HAL is a multi-disciplinary open access archive for the deposit and dissemination of scientific research documents, whether they are published or not. The documents may come from teaching and research institutions in France or abroad, or from public or private research centers.
L'archive ouverte pluridisciplinaire HAL, est destinée au dépôt et à la diffusion de documents scientifiques de niveau recherche, publiés ou non, émanant des établissements d'enseignement et de recherche français ou étrangers, des laboratoires publics ou privés. 
Robustness of SST teleconnections and precursory patterns associated with the Indian Summer Monsoon

Ghyslaine Boschat ${ }^{1}$, Pascal Terray, Sébastien Masson

\section{LOCEAN/IPSL, CNRS/IRD/UPMC/MNHN, Paris, France}

Revised version, Climate Dynamics

May 2011

${ }^{1}$ Corresponding author address : Ghyslaine Boschat, LOCEAN-IPSL, Université Pierre et Marie Curie, BP100 - 4 place Jussieu, 75252 Paris cedex 05, France.

Tel : +33144272329

E-mail : gbolod@locean-ipsl.upmc.fr 


\begin{abstract}
This work attempts to reconcile in a common and comprehensive framework the various conflicting results found in the literature regarding Indian Summer Monsoon (ISM) rainfall-Sea Surface Temperature (SST) relationships, especially the links with El-Niño Southern Oscillation (ENSO) and the Indian Ocean Dipole (IOD).

To do so, we first examine the linear relationships between ISM rainfall and global SST anomalies during 1950-1976 and 1979-2006 periods. Our results highlight the existence of significant modulations in SST teleconnections and precursory patterns between the first (June-July, JJ) and second part (August-September, AS) of the monsoon. This JJ-AS rainfall dichotomy is more pronounced after the 1976-77 climate regime shift and tends to blur the global ISM-ENSO signal during the recent period, leading to an apparent weakening of this relationship at the seasonal time scale. Although ISM rainfall in JJ and AS is still strongly linked to ENSO over both periods, the leadlag relationships between ENSO and AS Indian rainfall has changed during recent decades. Indeed, ENSO variability in the preceding boreal winter has now a significant impact on rainfall variability during the second half of ISM.
\end{abstract}

To evaluate in more details the impact of this JJ-AS dichotomy on the ISM-ENSO-IOD relationships, ISM correlations are also examined separately during El Niño and La Niña years. Results indicate that the early onset of El Niño during boreal spring causes deficient monsoon rainfall in JJ. In response to weaker monsoon winds, warm SST anomalies appear in the west equatorial IO, generating favorable conditions for the development of a positive IOD in AS. Local air-sea processes triggered by the SST anomalies in the eastern node of IOD seem, in turn, to have a more active role on AS rainfall variability, as they may counteract the negative effect of El Niño on ISM rainfall via a modulation of the local Hadley circulation in the eastern IO. The JJ-AS rainfall dichotomy and its recent amplification may then result from an enhancement of these IO feedbacks during recent El Niño years. This explains why, although El Niño events are stronger, a weakening of the ISM-ENSO relationship is observed at the seasonal scale after 1979. Results during La Niña years are consistent with this hypothesis although local processes in the Southeast IO now play a more prominent role and act to further modulate ISM rainfall in AS.

Finally, our results highlight the existence of a biennal rhythm of the IOD-ENSO-ISM system during the recent period, according to which co-occurring El Niño and positive IOD events tend to be followed by a warming of the IO, a wet ISM during summer and, finally, a La Niña event during the following boreal winter.

Keywords: Indian Summer Monsoon; Sea Surface Temperature; ENSO;Indian Ocean Dipole. 


\section{Introduction}

Interannual variability of the Indian Summer Monsoon (ISM) rainfall has a great impact on the economy of India and surrounding countries. Long-range forecasting of ISM rainfall is thus a matter of great concern for the people of South Asia, but is still a challenging scientific problem (Gadgil et al., 2005). To achieve this goal, a proper understanding of how external slow boundary forcings modulate ISM variability is required. It is with this aim that many works have examined the links between ISM rainfall and various modes of variability in the Indo-Pacific region, since the seminal works of Blanford (1884) and Walker (1924).

In most of these past studies, a strong statistical relationship has been observed between ISM rainfall and El Niño-Southern Oscillation (ENSO) (Rasmusson and Carpenter, 1983; Webster and Yang, 1992; Shukla, 1987; Webster et al., 1998; Wang, 2006). Although ENSO accounts for only about $30 \%$ of ISM variability (see the correlations in Table 2 for further details), it has been shown that El Niño (La Niña) events tend to favor deficit (excess) ISM rainfall (Shukla and Paolino, 1983; Ju and Slingo, 1995). However, the relationship between ENSO and ISM is complex and not systematic (Krishna Kumar et al., 1999, 2006; Kinter el al., 2002; Annamalai and Liu, 2005; Kucharski et al., 2007, 2008; Wang et al., 2008). As a notable example, the 1997-98 El Niño event, despite its intensity, produced only marginal rainfall anomalies over India, while the much weaker 2002 El Niño was associated with a very severe drought (see Fig. 1; Slingo and Annamalai, 2000; Gadgil et al., 2007). In addition, it has been noticed that ISM variability during recent decades may be more significantly influenced by the decaying phase of El Niño and the warming of the Indian Ocean (IO) which follows El Niño events in the late boreal winter and spring (Yang et al., 2007; Du et al., 2009; Park et al., 2010; Boschat et al., 2010). As an illustration, ISM rainfall was above normal in 1973, 1983 and 1988 following the El Niño events of 1972-73, 1982-83 and 1986-87 (see Fig. 1). In other words, the links between ENSO and ISM are not yet properly understood, particularly in the context of global warming (Gershunov et al., 2000; Ashrit et al., 2003; Annamalai et al., 2007; Kucharski et al., 2007, 2008, 2009; Abram et al., 2008; Cai et al., 2009a).

Faced with observations of a recent weakening of the ISM-ENSO relationship, more and more studies have focused on the role played by the IO on ISM variability (Ashok et al., 2001, 2004; Gadgil et al., 2004, 2005, 2007; Krishnan et. al., 2003; Krishnan and Swapna, 
2009; Clark et al., 2000; Terray et al., 2003, 2005, 2007; Yang et al., 2007; Izumo et al., 2008; Park et al., 2010; Boschat et al., 2010). Although Sea Surface Temperature (SST) anomalies over the equatorial IO are not statistically associated with ISM rainfall (Gadgil et al., 2004, 2005, 2007; Ihara et al., 2007), a lot of attention has been paid to the Indian Ocean Dipole (IOD) over the years, with debate regarding its existence as an intrinsic mode of IO variability, its dependence with ENSO (Chang et al., 2006), as well as its relationship with ISM (Ashok et al., 2001, 2004; Gadgil et al., 2004, 2005, 2007; Loschnigg et al., 2003; Terray et al., 2005; Kulkarni et al., 2007; Drbohlav et al., 2007; Hong et al., 2008). However, even the most recent studies have obtained quite contradictory results on this subject. Indeed, while some authors, like Ashok et al. (2004) or Krishnan and Swapna (2009) suggest the existence of a positive relationship between positive IOD events and strong ISMs (as in the years 1961 and 1994, see Fig. 1), others insist on the fact that the IOD-ISM relationship is closely tied with the Tropical Biennial Oscillation (TBO; Meehl et al., 2002, 2003; Loschnigg et al., 2003; Terray et al., 2005; Drbohlav et al., 2007; Webster and Hoyos, 2010). In this scenario, positive IOD events are associated with a deficient monsoon during the current year, but the warm SST anomalies associated with these positive IOD events may contribute to the development of a stronger than normal monsoon during the next summer. The years 1982-83 and 1987-88 are good examples of this biennial rhythm (Fig. 1). However, as of today, the impact of IOD events, co-occurring with El Niño development in the Pacific, is still not well understood. For instance, the two strongest El Niño events of the last century, in 1982-83 and 1997-98, were both associated with IOD events, but ISM rainfall was deficient in 1982 and above normal in 1997 (Fig. 1). Therefore, an understanding of the role of IOD events on the ISM is also critical for improving ISM rainfall prediction (Gadgil et al., 2004, 2005, 2007).

Meanwhile, there have also been suggestions of significant extratropical influence on ISM variability, whether it be from the North Pacific (Peings et al., 2009), the North and South Atlantic (Srivastava et al., 2002; Kucharski et al., 2007, 2008 and 2009; Rajeevan and Sridhar, 2008) or the South IO (Terray et al., 2003, 2005, 2007). As an illustration, the Indian Ocean Subtropical Dipole (IOSD) mode (Behera and Yamagata, 2001) has been shown to play a significant role in influencing ISM, IOD and ENSO (Terray et al., 2005, 2007; Fischer et al., 2005; Terray, 2010; Yoo et al., 2010), particularly after the so-called 1976-77 climate shift (Terray and Dominiak, 2005). This climate shift refers to the alteration of the North Pacific SSTs associated with a deepening of the Aleutian low pressure system after 1977 (Nitta and Yamada, 1989). SSTs across the tropics have consistently risen since 1976-77, 
particularly in the IO (Terray, 1994), accompanied by notable changes in ENSO characteristics (Wang, 1994). The ENSO-ISM relationship has also been shown to weaken around this time (Kinter et al., 2002), which calls to question the potential impact of this climate shift on the teleconnection between ISM and IO SSTs.

Altogether, these recent studies have thus suggested the existence of significant precursory SST signals in the tropical and extra-tropical regions before the ISM onset (Boschat et al., 2010). Nevertheless, we need to bear in mind that a majority of these works have focused on a recent time-period, e.g. the period from the late 1970s onwards, which has benefitted from satellite coverage, and, hence, greater reliability in observational data. Therefore, can we really be certain of the robustness of these precursory signals and their validity for other time periods? This question is particularly relevant since ENSO precursors have already been shown to change significantly following the 1976-77 climate shift (Wang, 1995; Terray and Dominiak, 2005). In the context of a weakened ISM-ENSO relationship, it thus seems legitimate to ask ourselves whether ISM precursors have changed in a similar way during the recent period. Besides, a closer inspection of their mutual interaction could also eventually lead to a better ISM seasonal prediction. Note that these issues are particularly at stake, after the failure of the Indian Meteorological Department or international centres operational forecasts for the recent severe droughts of 2002, 2004 and 2009 (Gadgil et al., 2005; Rajeevan et al., 2006; Francis and Gadgil, 2010).

Overall, the purpose of the present study is thus to question the time-dependence and spatial robustness of previous findings, as far as ISM is concerned. Besides, more emphasis must also be given to the association between global SST patterns and ISM rainfall inside of the set of El Niño (or La Niña) events in order to examine probable causes for the collapse of the ISM-ENSO relationship during recent decades.

The paper is organized as follows: the datasets used are described in Section 2. Section 3 examines statistical relationships with ISM over the 1950-1976 and 1979-2006 periods, based on correlation analyses between ISM rainfall and various SST indices. These correlation analyses are then extended in Section 4, in order to assess the robustness of global ISM teleconnection and precursory patterns, before and after the 1976-77 climate shift. Finally, Section 5 aims to explore the association between these global SST patterns and ISM rainfall within the sets of El Niño and La Niña years. All the results are then summarized and discussed in Section 6. 


\section{Data and Methods}

In this study, we use the ISM rainfall data derived from the rain gauge in situ observations (Parthasarathy et al., 1995). This dataset is updated routinely by the Indian Institute of Tropical Meteorology and consists of an area-weighted average of 306 rain gauges distributed across India. The ISM rainfall time series is computed over the whole June to September (JJAS) season, as well as separately during the early part in June-July (JJ) and later part of the season in August-September (AS), following the results of Boschat et al. (2010).

To examine the SST anomalies associated with ISM variability, our analysis makes use of the Hadley Centre sea ice and sea surface temperature dataset (HadISST1.1) available from 1871 to 2007 (Rayner et al. 2003). To examine the associated atmospheric patterns, we also use Sea Level Pressure (SLP) time series from the monthly Hadley Center analyses, available from 1850 to 2005 (Allan and Ansell, 2006). Note that we have intentionally not used any reanalysis product in our study, as data assimilation systems have their limits due to changes in the assimilated data stream in the reanalysis (i.e. with the introduction of satellite data after 1979). This would certainly introduce some biases in our comparison of the ISM precursory signals before and after the climate shift observed in the late 1970s (Kinter et al., 2004). Note, however, that the Hadley center SST and SLP datasets may also have problems and flaws, but the results shown here are reproducible with the other reanalyses currently available (Hurrel and Trenberth, 1999).

Besides, the analysis of long-term SST time series has shown that the IO has undergone a significant secular variation associated with a $0.3^{\circ}$ or $0.5^{\circ} \mathrm{C}$ shift to a warmer state during the $20^{\text {th }}$ century (Nitta and Yamada, 1989; Terray, 1994; Clark et al., 2000; Alory et al., 2007). In order to remove this global warming effect from the SST and SLP timeseries, a preprocessing step is applied to the full period of each dataset. We use the STL additive scheme (SeasonalTrend decomposition procedure based on Loess), developed by Cleveland et al. (1990) for this purpose, as it allows us to extract the interannual signal from the potentially noisy and non-stationary SST and SLP observations. Interannual anomalies are then defined as deviations from a (non-linear) long-term trend and a "local" annual cycle estimated by the STL scheme (for further detail see Terray, 2010). Note that our results are robust and remain unchanged by the use of different parameters in the STL filtering procedure. 
Once the preprocessing step completed, this study then focuses more specifically on two periods: 1950-1976 and 1979-2006. However, results shown here are not sensitive to the choice of this break point year around the 1976-77 climate shift (not shown). Simple correlation and regression analyses are used to assess the associations between ISM rainfall and SST modes during the two periods. The significance of the cross-correlation coefficients is assessed by the phase-scrambling bootstrap test described in Ebisuzaki (1997).

\section{Robustness of predictive relationships between ISM rainfall and key SST indices in the Indo-Pacific region}

In this section, we wish to test the robustness of statistical relationships, which have been established in Boschat et al. (2010), between ISM rainfall and various modes of SST variability in the Indo-Pacific region during the recent decades (1979-2007). The aim is thus to extend this correlation anlaysis to the period before the 1976-77 climate shift. Before doing so, the variability of ISM rainfall is examined and compared during 1950-1976 and 19792006, in order to justify the choice of these two time periods in the following analyses.

Table 1 summarizes the spatio-temporal definitions of the key-SST indices used here to represent various modes of variability over the Indo-Pacific region, as well as the references in the literature which have first proposed to use these "classical" time series. Note that these indices are computed from the detrended SST dataset over the two time periods. In light of previous findings, we have chosen to use the Niño3.4 index to represent ENSO. Nevertheless, results in this section remain unchanged by the use of the Niño3, Niño4 or Niño3.4 timeseries, which suggests that the spatial pattern of SST in the tropical Pacific does not significantly affect the ISM-ENSO teleconnection, in line with the results of Rajeevan and Pai (2007).

\section{a) ISM rainfall time series during 1950-1976 and 1979-2006}

In order to compare the variability of ISM rainfall during 1950-1976 and 1979-2006, standardized rainfall time series for the full ISM (JJAS), as well as the first (JJ) and second (AS) parts of ISM are shown in Figs. 2a and b. In these figures, the dashed horizontal lines designate the $+/$ - one standard deviation and help to identify anomalous ISM years during 
each period. The phase relationship with ENSO is also examined by simple comparison with the JJAS Niño3.4 standardized SST time series (dashed black curve in Fig. 2).

During 1950-1976, ISM rainfall anomalies show a rather strong coherency inside the monsoon season, and rainfall variability in JJAS, AS and JJ are highly correlated with a cross correlation of 0.78 between JJAS and JJ and of 0.88 between JJAS and AS rainfall time series (Fig. 2a). Indeed, during extreme monsoon years, the positive and negative rainfall peaks in JJAS coincide well with maxima and minima of rainfall in both $\mathrm{JJ}$ and AS and this is particularly true for the drought years (eg 1965, 1972 and 1974). Another remarkable characteristic of this period is the quite steady and out-of-phase relationship between ISM rainfall and the JJAS Niño3.4 SST time series with a correlation of -0.64 significant at the 99\% confidence level. Many wet ISMs coincide with La Niña events in JJAS (eg 1956, 1975), and most dry ISMs with El Niño conditions (eg 1951, 1957, 1965, 1972) during this period. Note however that there are exceptions to this rule, as in 1961. This wet ISM year, which is the strongest monsoon on record for the full 1950-2006 period (see Fig. 1), is also identified as one of the strongest IOD episodes and more specifically one of the two positive IOD events (with 1967), which occurred in the absence of an El Niño before the 1976-77 climate shift (see Fig. 1; Fischer et al., 2005). The 1967 IOD event, however, is not associated with any significant ISM rainfall anomalies in JJAS, JJ or AS (Fig. 2a).

The evolution of ISM rainfall seems to be substantially different during the 1979-2006 period, with both a stronger variability within the ISM season and a weaker synchronous relationship with ENSO (Fig. 2b). Unlike what is observed before 1976, extreme ISM years generally coincide with a peak in ISM rainfall either in JJ or AS, but rarely with both at the same time. Interestingly, severe droughts seem to be mostly associated with rainfall anomalies in JJ (eg 1982, 1987, 2002) whereas 3 of the 4 strong ISMs are due to highly positive rainfall anomalies during AS (eg 1983, 1988, 1990). Consistent with this weaker persistence of rainfall anomalies, the JJ and AS rainfall time series are now generally decorrelated with an insignificant correlation of 0.11 , as opposed to the higher significant value of 0.38 obtained from the earlier period. The rainfall evolution has sometimes even conflicting tendencies within the summer season as in 1992, 1998 and 2001: in these cases, JJAS ISM rainfall anomaly simply results from a compensation of opposite rainfall tendencies during JJ and AS. 
In line with this apparent erratic behavior, the relationship between JJAS ISM rainfall and Niño3.4 SST time series has also become quite ambiguous (correlation of -0.40) and although both time series remain out-of-phase during the beginning of the period, a more chaotic ISMENSO relationship seems to set in by the early 90s (Fig. 2b). Indeed, although many dry ISM events still coincide with El Niño conditions in JJAS (1982, 1987 and 2002), the $1997 \mathrm{El}$ Niño, on the other hand, is associated with slightly above normal ISM rainfall, while other recent drought years like 2004 are not even characterized by any warming in the Pacific during summer (Fig. 2b). Similarly, the wet ISM years of 1983 and 1994 are not linked to La Niña episodes and it seems that wet ISMs are generally more associated with the decaying phase of El Niño events as in 1983, 1988 and 1998. Note that in these cases, the positive rainfall anomalies are also restricted to the second half of ISM (eg AS).

Links with IOD events may also be suggested here, reflecting the complexity of recent ISMENSO-IOD relationships. Indeed, the 1994 ISM stands out both as one of the strongest wet ISM year of the recent decades and a strong positive IOD, which occurs independently from ENSO during boreal summer and fall (see Figs. 1 and 2b; Fischer et al., 2005; Drbohlav et al., 2007). However, this 1994 IOD event is associated with rainfall anomalies in JJ rather than AS as we would expect if IOD is influencing the monsoon. The positive rainfall anomalies observed in the boreal summer of the $1997 \mathrm{El} \mathrm{Niño} \mathrm{event} \mathrm{have} \mathrm{also} \mathrm{been} \mathrm{linked} \mathrm{to} \mathrm{the}$ occurrence in fall of a positive IOD event (Slingo and Annamalai, 2000; Ashok et al., 2001). However, El Niño and IOD events also co-occured in 1982, 1987 and 2002, but all of these years are marked by highly deficient rainfall over India (Fig. 2a).

Overall, the analysis of these ISM rainfall time series thus suggests a potentially different behavior of ISM rainfall during the two time periods, which can justify a separate examination of the pre-1976 and post-1976 periods in the following sections. It has also suggested a more erratic behavior of rainfall variability within the JJAS season during recent decades, which is consistent with a weaker ISM-ENSO relationship despite the fact that 1982-83 and 1997-98 were two of the strongest events in the $20^{\text {th }}$ century. The possible causes for this recent collapse of the synchronous ISM-ENSO relationship will be discussed in Section 5.

\section{b) Robustness of predictive relationships}


In this section, we examine the epochal variations in the linear relationships of ISM rainfall with modes of interannual variability over the Indo-Pacific region. Table 2 shows results from a correlation analysis between ISM rainfall indices (in JJAS, JJ and AS) and key SST indices for the 1950-1976 and 1979-2006 periods. To facilitate the comparison with previous findings, we use the same spatio-temporal definitions as in Boschat et al. (2010) for the selected SST indices (see Table 1). Among these time series, four precede ISM and may thus have a potential for ISM rainfall long-range forecasting: the $\operatorname{IOD}(-1)$ index defined during the previous fall in September-October-November (SON), the Niño(-1) during the previous winter in December-January (DJ), the SEIO in February-March (FM) and the IOB in AprilMay (AM). Two of these indices are also considered after the ISM in order to test the biennial nature of their relationships with ISM rainfall: the $\operatorname{IOD}(0)$ defined during the following fall (in SON), and the Niño(0) during the following winter (in DJ). These two time series are plotted in Fig.1. The eastern and western nodes of IOD have also been taken into account in this analysis. This will provide a clearer understanding of the possible linkages, if any, between IOD and ISM variability in the framework of the TBO.

To begin with, results on a seasonal scale (e.g. JJAS) show that ISM rainfall is most significantly correlated with SEIO and Niño(0) time series during both time periods (Table 2). However, correlation values are generally weaker after 1979, and the most important decrease is recorded with the Niño(0) index, from -0.64 during 1950-1976 to -0.40 during 1979-2006: a result in line with recent studies (Kinter et al., 2002; Kucharski et al., 2007 among others). In contrast, the SEIO index is strongly correlated with ISM rainfall in the following summer during both periods. Note however that this significant SEIO-ISM relationship is exclusively restricted to the AS season, which is consistent with the higher predictability of the late ISM season already suggested by Terray et al. (2003), Park et al. (2010) and Boschat et al. (2010).

Meanwhile, our analysis also highlights the complexity of the ISM-ENSO relationship if we look more carefully at the relationships within the ISM (e.g. in JJ and AS). Before 1976-77, ISM rainfall in JJAS, JJ or AS is strongly associated with Niño(0), but the relationships with Niño(-1) are always insignificant. This suggests that a weak (strong) ISM occurs during the developing year of El Niño (La Niña), but is not related to the previous ENSO state. After 1976-77, the association of ISM rainfall in JJ or AS with Niño(0) becomes insignificant and the correlation with Niño(-1) reaches a significant maximum of 0.50 for the AS rainfall time series. These results thus suggest a 'phase shift' rather than a weakening of the ENSO-ISM 
relationship during recent decades, since AS rainfall is now significantly related to the state of the Pacific in the previous boreal winter. The statistical importance of the Niño(-1) index after 1979 was already noted by Boschat et al. (2010) and may reflect the influence of the strong 1982-83 and 1997-98 El Niño events on the recent ISM rainfall variability. Besides, our analysis also confirms the parallel evolution of the Niño(-1) and IOB indices evoked in previous studies (Yang et al., 2007; Du et al., 2009; Boschat et al., 2010), as both indices are marked by comparable correlation values with ISM rainfall in AS during both periods. Since the IOB SSTs act largely in response to ENSO, the IOB-ISM rainfall correlations in Table 2 are entirely consistent with the speculation of a phase shift rather than a weakening of the ENSO-ISM relationship after 1976.

On the other hand, results with the IOD index reflect rather well the conflicting theories found in the literature on this subject. Extreme IOD events occurred repeatedly in the more recent periods (see Fig. 1), and have been suggested as a major cause for the weakening of the "historical" ENSO-ISM relationship (Ashok et al., 2001, 2004, Abram et al., 2008). However, correlations with the $\operatorname{IOD}(0)$ index are systematically weak over the two periods, as much on a seasonal scale as within the season, and the values obtained are always negative. Indeed, it has been argued that when a positive IOD event occurs, both poles of the IOD contribute to the surplus rainfall over India (Ashok et al., 2001, 2004). But, the results in Table 2 suggest only a significant but reversed contribution from the western node of the IOD during early boreal summer (correlation of -0.47 with JJ rainfall before 1979 and -0.34 after), while correlation with the eastern node of IOD is near zero and insignificant for all the rainfall indices, and fails to reproduce a clear out-of-phase relationship with the western node. These results suggest that the ENSO signal dominates the SST variability over the IO, which is in line with previous analyses (Gadgil et al., 2004, 2005; Ihara et al., 2007). However, this does not rule out the possibility that the IOD contributes to neutralize the ENSO-induced anomalous subsidence over India when IOD and El Niño co-occur (see Section 5).

Meanwhile, results with the $\operatorname{IOD}(-1)$ index are in better agreement with its possible role in the framework of the TBO, but only for the recent period. The moderate, but significant, 0.38 correlation obtained between $\operatorname{IOD}(-1)$ and AS rainfall after 1979 is almost exclusively due to the western node of the IOD ( 0.51 correlation). However, no definite conclusion can be drawn at this point regarding the statistical robustness of this IOD(-1)-ISM relationship, nor its underlying causes. Indeed, correlation with the $\operatorname{IOD}(-1)$ index is weak before 1979 , 
throughout the ISM season and with both nodes, implying again that statistics after 1979 may be biased and linked to the strong El Niño/IOD events of this period. As a result, we still need to investigate whether the western node of IOD actually plays a significant precursory role in the variability of the following ISM, or whether these anomalies are merely part of the slow IO warming which occurs after an El Niño and are thus intrinsically linked to the IOB and Niño(-1) indices (Drbohlav et al., 2007; Sooraj et al., 2009; Hong et al., 2010). The parallel evolution of the correlations of AS rainfall with the IOB, Niño(-1) and the western node of the IOD(-1) in Table 2 supports this last hypothesis. Note, besides, that this strengthening of the ISM in the following year concerns essentially the second part of the season (e.g. AS, see Table 2), which once again points to a higher predictability of the AS rainfall. This is the case in 1973, 1983, 1988 and 1998, when AS rainfall is highly positive following the cooccurrence of IOD and El Niño events in 1972, 1982, 1987 and 1997 (see Figs. 1 and 2).

Altogether, results from this section suggest a recent 'phase shift' in the ISM-ENSO relationship rather than a weakening, with an apparently stronger influence of the inter-related Niño(-1), IOB and IOD(-1) indices on the ISM after 1979, especially in AS. Table 2 also highlights the increasing significance of IO precursory signals after 1979, and in particular of the IOD(-1), IOB and SEIO indices.

\section{Global teleconnections and precursory SST signals associated with ISM rainfall during 1950-1976 and 1979-2006}

In an attempt to examine more objectively the statistical relationships with ISM rainfall, a correlation analysis is now carried out with global SST and SLP anomalies rather than predefined SST indices in the Indo-Pacific region. In light of previous results, these correlations are computed separately with ISM rainfall in JJ (Figs. 3 and 4) and AS (Figs. 5 and 6). The SST and SLP teleconnections and precursory patterns associated with each part of the monsoon season are then compared over the 1950-1976 and 1979-2006 periods.

\section{a) Correlations with ISM rainfall in $\mathbf{J J}$ :}

Overall, results for the JJ rainfall time series stress the importance of ENSO. Indeed, Figs. 3 and 4 indicate that, during both time periods, deficient (excess) $\mathrm{JJ}$ rainfall is significantly linked to the development of El Niño (La Niña) conditions in the tropical Pacific Ocean, 
where warm (cold) SST anomalies appear in boreal spring and consistently grow until the end of the year, in relation to a dry (wet) JJ season over India. Significant SLP anomalies are also observed over the tropical Indo-Pacific region during boreal summer, as part of the Southern Oscillation pattern, and illustrate the influence of El Niño (La Niña) on ISM through the eastward (westward) shift of the Walker circulation (Fig. 4). There are also suggestions that ISM rainfall in JJ may be linked to an earlier onset of ENSO during both periods, as significant SST anomalies appear as early as in FM in the tropical Pacific (Fig. 3).

Although this ISM-ENSO relationship in JJ seems quite robust over both time periods, the characteristics of the ENSO signal displayed in Figs. 3 and 4 seem to differ from one period to another. First, the ENSO-related SST and SLP anomalies are generally weaker during 1979-2006, in line with the theory of a weakening of the ISM-ENSO relationship in recent decades. Note also that the negative SLP anomalies over the north IO develop in JJ, one season after the positive SLP anomalies over the tropical Pacific Ocean during the recent period, whereas both poles of this tropical SLP oscillation appear simultaneously in AM during the earlier period. Finally, another noteworthy characteristic of the recent ISM-ENSO relationship, as far as JJ rainfall is concerned, is that SST anomalies appear in a rather central region of the tropical Pacific, recalling suggestions of a link between recent ISM rainfall variability and 'Modoki-type' El Niños (Ratnam et al., 2010). However, this cold central Pacific pattern is only flanked by warm anomalies on its western side. This central ENSO signal then propagates eastwards, in contrast with the more westward propagation observed during the 1950-1976 period (Federov and Philander, 2000, 2001; Wang and An, 2002; Trenberth et al., 2002; Mc Phaden and Zhang, 2009).

In spite of these altered characteristics, the ISM-ENSO teleconnection stands out as a dominant feature during the first part of the ISM season for both periods. On the other hand, there are no hints of any IOD-related SST or SLP patterns in the boreal fall either preceding or following the ISM season during both periods (Figs. 3 and 4).

Focusing now on SST precursory patterns before ISM onset, there are suggestions of significant relationships with SST anomalies between northern Australia and Indonesia (Nicholls, 1995) or with an anomalous SST dipole in the North Atlantic (Srivastava et al., 2002) persisting from ON to FM during 1950-1976 (Fig. 3). But, these ISM precursory SST signals are generally weak and scarcely significant after 1979. The implications of these 
results in terms of $\mathrm{JJ}$ rainfall predictability are thus rather pessimistic. However, a more robust SST signal is found in the North Pacific Ocean during boreal spring (Peings et al., 2009). These SST anomalies are collocated with significant SLP anomalies in the form of a North Pacific Oscillation (NPO) SLP pattern from DJ to AM during 1950-1976 and in AM after 1979 (Fig. 4). The NPO is a well-known precursor of ENSO, and may thus influence ISM rainfall variability via its forcing on ENSO. In Figs. 3 and 4, the anomalous SST and SLP patterns are consistent with the "seasonal footprinting mechanism" which was proposed to explain this NPO-ENSO teleconnection (Vimont et al., 2003 and 2009; Alexander et al., 2010). In this scenario, the positive (negative) SLP anomalies forming the southern node of the NPO pattern (Fig. 4) are associated with an increase (reduction) of the trade winds in the subtropical North Pacific (not shown); this imparts a cold (warm) local SST 'footprint' (Fig. 3) which modulates the wind variability in the equatorial western Pacific, and leads to the development of a La Niña (El Niño) event through the generation of oceanic Kelvin waves.

\section{b) Correlation with ISM rainfall in AS:}

Correlations of SST and SLP fields with AS rainfall timeseries yield results that are substantially different to those observed in JJ, and highlight the existence of a certain JJ-AS dichotomy in ISM-SST and ISM-SLP relationships, especially during the recent period (Figs. 5 and 6).

During the 1950-1976 period, results in AS show a robust ISM-ENSO relationship but point towards much more significant SLP and SST precursors for Indian rainfall in AS than JJ. Indeed, Figs. 5 and 6 (left panels) recapture a significant and very comparable ISM-ENSO relationship to that observed in $\mathrm{JJ}$ for the same period. This is consistent with the maximum correlation values obtained with Niño(0) before 1976-77 in Table 2 (-0.47 in JJ and -0.59 in AS). However, significant SST anomalies in other regions seem to have gained importance for AS rainfall variability and predictability. This is the case in the tropical Atlantic Ocean, where warm (cold) SST anomalies persist from ON to FM in relation to a wet (dry) AS ISM season before 1976 (Fig. 5). However, this SST signal is opposite to the summer AtlanticISM relationship proposed by Kucharski et al. (2007, 2008 and 2009), and the lack of significant SLP anomalies in this region sheds a doubt on its potential impact on AS rainfall variability (Fig. 6). Meanwhile, an anomalous SST dipole is also observed from ON to AM in the south IO, associated with a significant modulation of the intensity of the Mascarene High 
during FM (Figs. 5 and 6). This is consistent with the occurrence of a subtropical dipole event in the south IO (Behera and Yamagata, 2001). The persistent warm (cold) anomalies in the southeastern IO associated with these subtropical dipole events have been shown to play a significant role on ISM variability, via a modulation of the inter-hemispheric moisture transport or the position of the Mascarene High in the IO (Terray et al., 2003, 2007; Boschat et al., 2010). In Fig. 6, the northward propagation of negative (positive) SLP anomalies in the Indian sector from $\mathrm{AM}$ to $\mathrm{AS}$ is consistent with the dynamical processes detailed in these earlier studies. Note that these results are also in line with the increased influence of the SEIO index in AS in Table 2 (0.16 correlation in JJ and 0.49 in AS during 1950-1976). Besides, it seems important to point out that the anomalous SST and SLP dipoles associated with the NPO also prevail as highly significant and therefore robust precursors for AS rainfall during the 1950-1976 period (Figs. 5 and 6). Altogether, the persistence and emergence of these significant precursory signals in both the North Pacific and Indian oceans thus reflect the higher predictability of AS rainfall, while also introducing a certain JJ-AS dichotomy in ISMSST statistical relationships during the 1950-1976 period.

This JJ-AS dichotomy is even more pronounced during the 1979-2006 period, as this time, correlation patterns in AS (Figs. 5 and 6, right panels) differ more substantially from results in JJ (Figs. 3 and 4), as well as more generally from those observed during the same AS season of the 1950-1976 period (Figs. 5 and 6, left panels). In line with the hypothesis of a 'phaseshift' of the ISM-ENSO relationship (see Table 2, in AS), Figs. 5 and 6 show that ISM rainfall in AS is now significantly linked to the decaying phase of ENSO rather than its development. This intense precursory signal in the tropical Pacific is a unique characteristic of the recent period and of the AS season as it is not seen during the 1950-1976 period nor during $J J$ of the recent period. Nevertheless, we must be careful about the implications of these results for ISM rainfall predictability, as composites of extreme ISM events during this period (not shown) indicate that this dominant signal in AS is largely due to the wet monsoons of 1983 and 1998, which followed the two strongest El Niño events of the $20^{\text {th }}$ century (see Boschat et al., 2010). Based on results shown in Figs. 5 and 6, it thus seems that the most robust precursory signals for AS Indian rainfall stem from extratropical regions in the North Pacific and South IO, as these significant patterns are seen to persist during both periods, several months before the ISM onset, and concern both the weak and strong ISMs.

Correlation patterns in AS during 1979-2006 also illustrate a biennial rhythm of the IOD- 
ENSO-ISM system, according to which an El Niño event tends to be preceded by decreased AS rainfall during boreal summer, a positive IOD pattern during fall, and followed by a basinwide warming of the tropical IO which persists until the next spring and, eventually, leads to enhanced AS rainfall and a La Niña event in the following year. The SST and SLP anomalies in Figs. 5 and 6 are consistent with these time and phase relationships, as well as the dynamical processes which have been shown to feed this biennial system, and influence the late ISM season (for further details see Yang et al., 2007; Sooraj et al., 2009; Boschat et al., 2010; Hong et al., 2010). Note that this biennial tendency is also consistent with the significant correlation values obtained with the $\operatorname{IOD}(-1)$, Niño(-1) and IOB indices in AS for the recent period in Table 2.

\section{Modulation of ISM rainfall during EI Niño and La Niña years (1950-2006)}

Overall, our previous analyses have shed a light on the existence of significant modulations in ISM teleconnections and precursory signals between the first (JJ) and second part (AS) of the monsoon season, and this especially after the 1976-77 climate shift. ISM rainfall variability is strongly linked to ENSO during both 1950-1976 and 1979-2006 time periods as the relationship with ENSO is still highly significant for JJ and AS rainfall averages separately. However, the increased JJ-AS dichotomy observed after 1979 seems to blur the global ISMENSO signal, leading to an apparent weakening of these relationships at the seasonal time scale during the recent decades.

So far, this weakening has been attributed to a broad range of phenomena, ranging from changes in atmospheric fields due to global warming (Krishna Kumar et al., 1999), to changes in tropical Pacific SST patterns (Krishna Kumar et al, 2006) or tropical Atlantic during boreal summer (Kucharski et al., 2007, 2008, 2009), to the more frequent co-occurrence of positive IODs and El Niño events during recent decades (Ashok et al., 2001, 2004; Krishnan and Swapnan, 2009), possibly also due to global warming (Abram et al., 2008; Ihara et al., 2008, 2009; Cai et al., 2009b, 2009c). Collectively, these studies suggest that more emphasis must be given to the association between global SST patterns and ISM rainfall inside of the set of El Niño (or La Niña) events, to examine probable causes for the failure of the ISM-ENSO relationship during the developing year of specific events. However, none of these works have drawn particular attention to the JJ-AS rainfall dichotomy observed during recent decades and evaluated its link to the recent modulation of the ISM-ENSO relationship. 
In the following paragraphs, a correlation analysis is thus carried out between JJ and AS ISM rainfall and global SST and SLP fields inside of the sets of El Niño and La Niña years, in order to analyze what may cause a modulation at the $2^{\text {nd }}$ order of ISM rainfall during each phase of ENSO. The El Niño (La Niña) years entering in this correlation analysis are selected over the entire 1950-2006 period, upon a 0.5 (-0.5) $\sigma$ of the Niño3.4 index in DJ. These wider criteria and extended period allow us to gather a larger amount of years for the analysis and therefore obtain more robust results.

\section{a) EI Niño years}

To begin with, the SST and SLP composites during JJ and AS computed from 16 selected El Niño years (1951, 1957, 1963, 1965, 1968, 1969, 1972, 1976, 1977, 1982, 1986, 1987, 1991, 1994, 1997 and 2002) display the development of well-known El Niño SST and SLP patterns in co-occurrence with a positive IOD pattern in the equatorial IO (Fig. 7a). Correlation analyses of ISM rainfall, separately in JJ and AS, with global SST and SLP anomalies are then carried out during these El Niño years.

Results show that ISM rainfall in JJ (Fig. 8a) is quite significantly influenced by the early development of El Niño conditions, compared to a "canonical" El Niño evolution (Fig. 7a), since correlations are significant and negative with SSTs over the central Pacific during the whole boreal summer. These correlations suggest that an early (late) El Niño onset causes deficient (excessive) ISM in JJ, associated with high (low) SLP anomalies and anomalous subsidence (ascent) over a large area extending from the Maritime Continent, to the North IO and the Asian continent (Fig. 8a). The correlation patterns between JJ rainfall and IO SSTs during these El Niño years mainly reflect the warming of the equatorial western IO in response to reduced evaporative heat loss and upwelling associated with weaker monsoon winds: this suggests that IO SST anomalies play a passive role during the first part of the ISM season. However, these correlation patterns also reveal interesting features about the dynamics of the ENSO-ISM-IOD relationships since the mean SST gradient across the equatorial IO is anomalously positive to the west in AS following an early El Niño and a dry ISM in JJ. This may induce an anomalous zonal positive SLP gradient to the east and promote anomalous westward zonal wind stress across the equatorial IO. In other words, these changes provide very favorable conditions for a positive IOD to develop during the second half of ISM and following months as suggested by (Loschnigg et al., 2003). 
The same correlation analysis for the AS season (Fig. 8b) shows that the relationships of AS rainfall with SST and SLP anomalies are entirely different. IO SSTs have more influence on the monsoon than vice-a-versa during the second half of the season. Indeed, Fig. $8 \mathrm{~b}$ indicates that, unlike results in JJ, the most significant anomalies associated with the second part of ISM are not located in the tropical Pacific, but in the southeast IO: a region where important air-sea feedbacks have been shown to operate during boreal summer (see Li et al., 2003). Indeed, the persistent cold anomalies along the coasts of Java and Sumatra are associated with positive SLP anomalies (Fig. 8b). Also, a significant anomalous cyclonic center is noted over the Arabian Sea and India during AS in relation to positive rainfall anomalies. This is consistent with a strengthening of the Bay of Bengal branch of ISM and a modulation of the local Hadley circulation over the eastern IO which can induce anomalous ascent and, hence, positive rainfall anomalies over the Indian subcontinent in AS. The positive correlations with SSTs in the south central IO are also consistent with an enhanced anticyclonic circulation over the eastern IO, as this circulation may reduce the intensity of the south-east trades in the Southern Hemisphere and, thus, decrease the evaporative heat loss (Terray et al., 2007). Put together, the SST and SLP patterns in Fig. 8b thus suggest that the anomalous anticyclone over the eastern node of the IOD may play a role in reducing the ENSO-induced subsidence over India during the second half of ISM.

In order to quantify the potential impact of these IOD-related anomalies in terms of ISM rainfall, a regression analysis between ISM rainfall and IOD-related time series in SeptemberOctober-November is also carried out during the same El Niño years. Results in Table 3 confirm that the west (east) node of the IOD has a significant association with JJ (AS) ISM rainfall $(-17 \mathrm{~mm} / \mathrm{month}$ compared to a mean value of $-12.06 \mathrm{~mm} / \mathrm{month}$ in $\mathrm{JJ}$ and -11.9 $\mathrm{mm} / \mathrm{month}$ compared to a mean value of $-16.72 \mathrm{~mm} /$ month in AS, respectively). Altogether, the two IOD nodes are thus playing opposite roles (passive for the west and and active for the east) with regards to ISM rainfall, while operating at different times. This can, at least partly, account for the JJ-AS dichotomy observed in ISM rainfall (consistent opposite values obtained in JJ and AS with the IOD time series in Table 3), as well as the rather conflicting results found in the literature on the IOD-ISM relationship (see Introduction of this paper).

Note, besides, that no significant correlations are observed over the tropical Atlantic Ocean during El Niño years (Fig. 8), even though the entire 1950-2006 period is considered: this 
result is not consistent with a possible contribution of Atlantic SSTs to the interdecadal modulation of the ENSO-ISM relationship (Kucharski et al., 2007, 2008, 2009) .

\section{b) La Niña years}

Similar analyses are now carried out during the negative phase of ENSO. The SST and SLP composites computed from 18 selected La Niña years (in 1950, 1954, 1955, 1964, 1966, 1967, 1970, 1973, 1975, 1983, 1984, 1985, 1988, 1995, 1998, 1999, 2000 and 2005) are characterized by reversed SLP and SST patterns in the Pacific during summer: however, anomalies in the IO differ from El Niño conditions as they feature the development of a SST dipole in the south IO rather than an IOD pattern (Fig. 7b). Note also that among these $18 \mathrm{La}$ Niña events, 9 follow the decaying phase of El Niño events while the 9 others correspond to lingering La Niña conditions in the Pacific.

The correlation with ISM rainfall in JJ and AS during these La Niña years (Fig. 9) shows patterns which are generally of the same sign as the SST and SLP composites in Fig. 7b. These correlations may thus be interpreted as a global modulation (ie enhancement or damping) of La Niña conditions during boreal summer, without any significant spatial modification of the "canonical" patterns (Fig. 7b). As during El Niño years, the first part of the ISM season seems to be mainly influenced by the state of the Pacific in JJ (Fig. 9a). Note however that, based on the years selected for this correlation analysis, this JJ ENSO signal may oppose years with an early onset of La Niña to those characterized by a late withdrawal of El Niño episodes.

On the other hand, results in AS highlight again the importance of IO anomalies and local coupled ocean-atmosphere processes during the second part of ISM, with the most significant SST anomalies observed in the north IO and in the form of a south IO dipole (Fig. 9b). Consistent with the existence of a JJ-AS dichotomy, the warming of the tropical IO in JJ enhances ISM rainfall in AS. In the south IO, the amplification from JJ to AS of negative SLP anomalies associated with the SST dipole is consistent with a strengthening of the trade-winds and an enhanced evaporation over the south central IO (Fig. 9b); both of which may enhance the interhemispheric moisture transport and, ultimately lead to positive ISM rainfall anomalies in AS (Terray et al., 2007; Boschat et al., 2010). 
Altogether, the modulation of ISM rainfall during La Niña years (compared to a "canonical" La Niña) occurs again through distinct processes in JJ and AS, although both act to enhance rainfall activity over India. The first part of the ISM season is mostly influenced by the early appearance of La Niña conditions, whereas local processes, particularly in the southeast IO, are at play during the second part of the season and amplify AS rainfall. Note that this JJ-AS dichotomy in ISM rainfall has also been observed during the decaying phase of El Niño events during recent decades (Boschat et al., 2010).

In conclusion, the existence of a JJ-AS dichotomy is observed inside both the sets of El Niño and La Niña years. Local interactions in the IO are mainly responsible for the modulation of ISM response in AS, although these physical processes differ among El Niño (La Niña) years. In constrast, the extratropical regions and Atlantic Ocean seem to play only a secondary role.

\section{Conclusion and discussion}

For years, many works have examined the links between ISM rainfall and various modes of interannual variability, such as ENSO or IOD (Webster et al., 1998; Wang, 2006). However, so far, these studies have obtained quite different, and at times contradictory results. Besides, no general consensus has yet been reached, as to explain the weakening of the ISM-ENSO relationship observed during recent decades (Krishna Kumar et al., 1999, 2006; Gershunov et al., 2000; Kinter et al., 2002; Ashok et al., 2004; Kucharski et al., 2009). This work builds upon these earlier studies and attempts to reconcile in a common and comprehensive framework the various conflicting results found in the litterature on ISM-SST relationships.

First, our results indicate the existence of a strong and steady ISM-ENSO relationship before the so-called 1976-77 climate shift. However, tropical Pacific SSTs do not provide any significant precursory signal for ISM rainfall during this 1950-1976 period. Instead, anomalous SST and SLP dipoles are observed during the previous boreal winter and spring in the North Pacific and South IO. These significant extratropical patterns are identified as potential ISM precursors but essentially for the second part of the monsoon season (eg. AS), which points to a certain dichotomy between the first and second parts of ISM as far as ISM predictability is concerned. Over the North Pacific, NPO-related SST and SLP patterns are detected before extreme ISM years. Further analysis suggests that this NPO-ISM predictive relationship is due to the apparent active role of the NPO in ENSO variability through the 
modulation of wind anomalies in the western Pacific (Vimont et al., 2003). These significant anomalies may thus be classified as "ENSO precursors" and signal the likely ENSO evolution during the following months. Local SST anomalies in the South IO during boreal winter and spring have also a significant relationship with ISM rainfall, but seem to evolve independently from ENSO during this period (Terray and Dominiak, 2005). Finally, it is important to stress that the Atlantic and equatorial IO (eg IOD) are devoid of any robust precursory SST signals during boreal fall and winter preceding ISM. Thus, they cannot provide any information on the type of ISM that may follow during this first epoch.

This distinction between the first (JJ) and second (AS) parts of the ISM season is even more pronounced after the 1976-77 climate shift. The SST and SLP teleconnection patterns associated with rainfall anomalies in AS are also very different, in many aspects, from those observed in the first period. Moreover, our results strongly support the hypothesis that the recent weakening of the ISM-ENSO relationship at the seasonal time scale may be an artefact of this increased subseasonal rainfall variability, since the relationship with ENSO is still highly significant for JJ and AS rainfall averages separately. Indeed, correlation results in AS suggest a 'phase shift' rather than a weakening of this ISM-ENSO relationship after 1979, with the appearance of an intense precursory signal for AS Indian rainfall in the tropical Pacific (and IO) during the previous boreal winter and spring, linked in particular to the decaying phase of the two strong El Niño events of 1982-83 and 1997-98. Our analysis of the recent period also confirms the importance of extratropical forcing on the whole ENSOmonsoon system, with precursory signals stemming from the North Pacific and South IO for AS rainfall (Terray et al., 2005; Peings et al., 2009). Besides, results in AS also highlight a more biennal tendency in the ENSO-ISM-IOD system during recent decades, according to which co-occurring El Niño and positive IOD events are followed by a warming of the IO, a wet ISM in the next summer and, finally, a La Niña event during the following winter (Meehl et al., 2003; Hong et al., 2010). Note however that this TBO signal may be also largely influenced by the 1982-83 and 1997-98 El Niño events. On the other hand, changes in the date of El Niño/La Niña onsets are probably the main factor contributing to ISM rainfall variability during $\mathrm{JJ}$.

Altogether, these analyses have thus shown that ISM is strongly linked to ENSO over both time periods. However, the increased JJ-AS dichotomy observed after 1979 tends to blur the ISM-ENSO signal, leading to an apparent weakening of this relationship at the seasonal time 
scale during the recent period. Note that this JJ-AS dichotomy may be linked to many factors, and may even be due to large intraseasonal variability which is being aliased by our bimonthly averaging. In order to gain a better understanding of this JJ-AS rainfall dichotomy and its link to the recent modulation of the ISM-ENSO relationship, we have finally examined the association between ISM rainfall and global SST and SLP fields, separately inside of the sets of El Niño and La Niña years.

The most notable features for the El Niño and La Niña years are (i) the sensitivity of ISM rainfall during $\mathrm{JJ}$ to the timing of ENSO onset and (ii) the importance of local air-sea feedbacks in the IO during the second half of boreal summer as key-factors for understanding the variability of ISM rainfall anomalies observed inside each set of events.

Our analysis suggests the following scenario as an important factor for modulating ISM response during El Niño events: an early onset of an El Niño causes a more deficient monsoon in JJ, which feeds back onto the IO by inducing warmer SST anomalies in the western equatorial IO associated with the reduced monsoon winds and Somali jet. These SST changes over the western IO provide, however, a very favourable environment for positive IOD development during the second half of ISM (Loschnigg et al., 2003). The local air-sea feedbacks associated with the SST anomalies in the eastern node of the IOD seem, in turn, to have a more active role on the second half of the monsoon, as they may counteract the effect of El Niño on ISM rainfall through a modulation of the local Hadley circulation over the eastern IO. In other words, the IO seems to play a passive role during the first part of ISM, but a more active role during the second part. Interestingly, this scenario provides a plausible explanation for the existence of a JJ-AS rainfall dichotomy during the El Niño developing year, and may also justify why most dry ISM years are associated with a dry JJ season during the recent period (see Fig. 2b).

Our results are thus partly consistent with the mechanism proposed by (Ashok et al., 2001, 2004) whereby the IOD is able to counteract the effect of El Niño on ISM rainfall - bearing in mind that the modulations we have described occur only at a second level during El Niño years. These authors argued that the anomalous convergence over the western pole of IOD induced by a positive IOD, enhanced the atmospheric circulation towards India and led to increased ISM rainfall; while the anomalous divergence over the eastern pole decreased the effect of El Niño-induced subsidence over India, by strengthening the meridional circulation 
over the eastern IO. However, we here suggest that only the eastern node of the IOD plays an active role in the modulation of ISM rainfall and, only, during the second half of ISM, whereas SST anomalies in the western node may be interpreted as a passive response to the atmospheric signal of an early developing El Niño and ensuing weak monsoon in JJ. We suspect that Ashok et al. $(2001,2004)$ were unable to reproduce this atmospheric forcing in the IO, as their results are derived from an atmospheric circulation model forced by observed SSTs (Krishna Kumar et al., 2005; Wang et al., 2005).

Yet, our results stress the key-importance of local ocean-atmosphere interactions for enhancing or counteracting the effect of El Niño on ISM rainfall, consistent with the second mechanism proposed by Ashok et al. (2004). The JJ-AS dichotomy observed more distinctively in recent El Niño events may then result from an enhancement of these IO feedbacks, with a more frequent occurrence of positive IODs. This, in turn, may explain why, although El Niño events are stronger, a global weakening of the ISM-ENSO relationship may be observed at the seasonal scale during recent decades..

A similar analysis for the La Niña years illustrates again the combined effects of ENSO and IO anomalies on wet ISMs. Indeed, results suggest that ISM rainfall anomalies in JJ are also influenced by the early onset of La Niña conditions in the Pacific, while local IO processes, particularly in the southeast, play an important role in the enhancement of ISM rainfall in AS (Terray et al., 2007; Park et al., 2010; Boschat et al., 2010). Note that these processes are consistent with recent results from Boschat et al. (2010), where the decaying phase of El Niño is considered. Indeed, they show that, during the 1979-2007 period, the mature phase of El Niño causes a delayed ISM onset and an anomalously deficient ISM in JJ, whereas local feedbacks particularly in the south IO enhance ISM rainfall activity in AS. In other words, the ocean-atmosphere interactions in the IO may also be responsible for a JJ-AS dichotomy in the set of the La Niña years or decaying El Niño years. This scenario also explains why most wet ISM events are associated with anomalously wet AS season during the recent period (Fig. 2b).

Altogether, our results thus highlight the importance of local processes for understanding the changes in the ISM-ENSO relationship during the recent period. But why are the IO oceanatmosphere interactions stronger in recent decades? Terray and Dominiak (2005) argued that this may be related to the sustained warming of the IO. Besides, several works have suggested a more frequent occurrence of extreme IOD events, possibly due to global warming (Abram et al., 2008; Ihara et al., 2008, 2009; Cai et al., 2009b, 2009c) or a natural decadal fluctuation 
of the tropical system (Zheng et al., 2010), developing in association with strong El Niño events. The causes for such changes in ENSO and IOD properties, cannot obviously be detected by our simple statistical analyses. The mechanims proposed in this work regarding the modulation of ISM rainfall variability, as well as the possible causes of these decadal fluctuations, need to be tested and validated through numerical experiments with coupled ocean-atmosphere models.

Acknowledgments: Financial support from the Indo-French CEFIPRA project $\left(\mathrm{N}^{\circ}\right.$ 3907/1) is acknowledged. The Hadley SST and SLP datasets were provided by the NOAA/OAR/ESRL PSD, Boulder, Colorado, USA, from their Web site at URL: http://www.cdc.noaa.gov/. Graphics have been prepared using the SAXO package of Sébastien Masson. We also thank the anonymous reviewers for their comments that improved this paper.

\section{References}

Abram NJ, Gagan MK, Cole JE, Hantoro WS, Mudelsee M (2008) Recent intensification of 
tropical climate variability in the Indian Ocean. Nat. Geosci. 1 :849-853.

Alexander MA, Vimont DJ, Chang P, Scott JD (2010) The impact of extratropical atmospheric variability on ENSO: testing the Seasonal Footprinting Mechanism using coupled model experiments. J Climate 23:2885-2901.

Allan R, Ansell T (2006) A new globally complete monthly historical gridded mean sea level pressure dataset (HadSLP2) : 1850-2004. J Climate 19:5816-5842.

Alory G, Wijffels S, Meyers G (2007) Observed temperature trends in the Indian Ocean over 1960-1999 and associated mechanisms. Geophys Res Lett 34:L02606. doi:10.1029/2006GL028044.

Annamalai H, Liu P (2005) Response of the Asian summer monsoon to changes in El Niño properties. Q. J. R. Meteorol. Soc. 131:805-831.

Annamalai H, Hamilton K, Sperber KR (2007) The South Asian summer monsoon and its relationship with ENSO in the IPCC AR4 simulations. J Climate 20:1071-1092.

Ashok K, Guan Z, Yamagata T (2001) Influence of the Indian Ocean Dipole on the relationship between the Indian monsoon rainfall and ENSO. Geophys Res Lett 28:44994502 .

Ashok K, Guan Z, Saji NH, Yamagata T (2004) Individual and combined influences of ENSO and the Indian Ocean Dipole on the Indian Summer Monsoon. J Climate 17:3141-3154.

Ashrit RG, Douville H, Rupa Kumar K (2003) Response of the Indian monsoon and ENSOmonsoon teleconnection to enhanced greenhouse effect in the CNRM coupled model. J. Meteor. Soc. Japan 81:779-803.

Behera SK, Yamagata T (2001) Subtropical SST dipole events in the southern Indian Ocean. Geophys Res Lett 28:327-330. 
Blanford HF (1884) On the connexion of Himalaya snowfall and seasons of drought in India. Proc. R. Soc. London 37:3-22.

Boschat G, Terray P, Masson S (2010) Interannual relationships between Indian Summer Monsoon and Indo-Pacific coupled modes of variability during recent decades. Climate Dyn doi:10.1007/s00382-010-0887-y.

Cai W, Sullivan A, Cowan T (2009a) Rainfall Teleconnections with Indo-Pacific variability in the WCRP CMIP3 Models. J. Climate 22:5046-5071.

Cai W, Cowan T, Sullivan A (2009b), Recent unprecedented skewness towards positive Indian Ocean Dipole occurrences and its impact on Australian rainfall. Geophys Res Lett 36:L11705. doi:10.1029/2009GL037604.

Cai W, Sullivan A, Cowan T (2009c) Climate change contributes to more frequent consecutive positive Indian Ocean Dipole events. Geophys Res Lett 36 :L23704. doi:10.1029/2009GL040163.

Chang P, and Coauthors (2006) Climate fluctuations of tropical coupled systems - The role of ocean dynamics. J Climate 19:5122-5174.

Clark CO, Cole JE, Webster PJ (2000) Indian Ocean SST and Indian summer rainfall: Predictive relationships and their decadal variability. J Climate 13:2503-2519.

Cleveland RB, Cleveland WS, McRae JE, Terpenning I (1990) A Seasonal-Trend Decomposition Procedure Based on Loess (with Discussion). J Official Statistics 6:3-73.

Drbohlav HKL, Gualdi S, Navarra A (2007) A diagnostic study of the Indian Ocean Dipole Mode in El Niño and non-El Niño years. J. Climate 20:2961-2977.

Du Y, Xie S-P, Huang G, Hu K-M (2009) Role of air-sea interaction in the long persistence of El Niño -induced North Indian Ocean warming. J Clim 22:2023-2038.

Ebisuzaki W (1997) A method to estimate the statistical significance of a correlation when the 
data are serially correlated. J Clim 10:2147-2153.

Fedorov AV, Philander SG (2000) Is El Niño changing? Science 288:1997-2002. Doi:10.1126/science.288.5473.1997.

Fedorov AV, Philander SG (2001) A Stability Analysis of Tropical Ocean-Atmosphere Interactions : Bridging Measurements and Theory for El Niño. J Climate 14:3086-3101.

Fischer AS, Terray P, Delecluse P, Gualdi S, Guilyardi E (2005) Two Independent Triggers for the Indian Ocean Dipole/Zonal Mode in a Coupled GCM. J Climate 18:3428-3449.

Francis PA, Gadgil S (2010) Towards understanding the unusual Indian monsoon in 2009. J. Earth Syst. Sci. 119:397-415.

Gadgil S, Vinayachandran PN, Francis PA, Gadgil S (2004) Extremes of the Indian summer monsoon rainfall, ENSO and Equatorial Indian Ocean Oscillation. Geophys Res Lett 31:L12213. doi: 10.1029/2004GL019733.

Gadgil S, Rajeevan M, Nanjundiah R (2005) Monsoon prediction - why yet another failure? Curr. Sci. 84:1713-1719.

Gadgil S, Rajeevan M, Francis PA (2007) Monsoon variability: Links to major oscillations over the equatorial Pacific and Indian oceans. Curr. Sci. 93, 182-194.

Gershunov A, Schneider N, Barnett T (2000) Low-frequency modulation of the ENSO-Indian monsoon rainfall relationship: signal or noise? J Climate 14:2486-2492.

Hong CC, Lu MM, Kanamitsu M (2008) Temporal and spatial characteristics of positive and negative Indian Ocean dipole with and without ENSO. J Geophys Res 113:DO8107. Doi:10.1029/2007JD009151.

Hong CC, Li T, LinHo, Chen YC (2010) Asymmetry of the Indian Ocean Basinwide SST Anomalies: Roles of ENSO and IOD. J Climate 23:3563-3576. 
Hurrell JW, Trenberth KE (1999) Global sea surface temperature analyses: multiple problems and their implications for climate analysis, modeling and reanalysis. Bull. Amer. Met. Soc., 80, 2661-2678.

Ihara C, Kushnir Y, Cane MA, de la Pena V (2007) Indian summer monsoon rainfall and its link with ENSO and the Indian Ocean climate indices. International Journal of Climatology 27:179-187.

Ihara, C, Kushnir Y, Cane MA (2008) Warming trend of the Indian Ocean SST and Indian Ocean dipole from 1880 to 2004 . J Climate 21 :2035-2046.

Ihara, C, Kushnir Y, Cane MA, Victor HP (2009) Climate change over the equatorial IndoPacific in global warming. J Climate 22:2678-2693.

Izumo T, De Boyer Montégut C, Luo J-J, Behera SK, Masson S, Yamagata T (2008) The Role of the Western Arabian Sea Upwelling in Indian Monsoon Rainfall Variability. J Climate 21:5603-5623.

Ju J, Slingo JM (1995) The Asian summer monsoon and ENSO. Quart J Roy Meteor Soc 121:1133-1168.

Kinter JL, Miyakoda K, Yang S (2002) Recent change in the connection from the Asian Monsoon to ENSO. J Climate 15:1203-1215.

Kinter J, Fennessy M, Krishnamurthy V, Marx L (2004), An evaluation of the apparent interdecadal shift in the tropical divergent circulation in the NCEP-NCAR reanalysis. $J$ Climate. 17:349-361.

Krishna Kumar K, Rajagopalan B, Cane M (1999) On the Weakening Relationship Between the Indian Monsoon and ENSO. Science. 284:2156-2159.

Krishna Kumar K, Rajagopalan B, Hoerling H, Bates G, Cane M (2006) Unraveling the Mystery of Indian Monsoon Failure During El Niño. Science. 314:115-119. Doi:10.1126/science.1131152. 
Krishnan R, Mujumdar M, Vaidya V, Ramesh KV, Satyan V (2003) The abnormal summer monsoon of 2000. J Climate 16:1177-1194.

Krishnan R., Swapna P (2009) Significance influence of the boreal summer monsoon flow on the Indian Ocean response during dipole events. J Climate 22:5611-5634.

Kucharski F, Bracco A, Yoo JH, Molteni F (2007) Low-frequency variability of the Indian Monsoon-ENSO relation and the Tropical Atlantic; The 'weakening' of the 1980s and 1990s. J Climate 20:4255-4266.

Kucharski F, Bracco A, Yoo JH, Molteni F (2008) Atlantic forced component of the Indian monsoon interannual variability. Geophys Res Lett. 35:L04706. Doi:10.1029/2007GL033037.

Kucharski F, Bracco A, Yoo JH, Tompkins A, Feudale L, Ruti P, Dell'Aquila A (2009) A Gill-Matsuno-type mechanism explains the tropical Atlantic influence on African and Indian monsoon rainfall. Quart J Roy Meteor Soc 135:569-579. Doi:10.1002/qj.406.

Kulkarni A, Sabade SS, Kripalani RH (2007) Association between extreme monsoons and the dipole mode over the Indian subcontinent. Meteorol. Atmos. Phys. 95:255-268.

Li T, Wang B, Chang CP, Zhang YS (2003) A theory for the Indian Ocean Dipole-Zonal Mode. J Atmos Sci 60:2119-2135.

Loschnigg J, Meehl GA, Arblaster JM, Compo GP, Webster PJ (2003) The Asian monsoon, the tropospheric biennial oscillation, and the Indian Ocean dipole in the NCAR CSM. J Climate 16:1617-1642.

McPhaden MJ, Zhang X (2009) Asymmetry in zonal phase propagation of ENSO sea surface temperature anomalies. Geophys Res Lett 36:L13703. Doi:10.1029/2009GL038774.

Meehl GA, Arblaster J (2002) The tropospheric biennial oscillation and the Asian-Australian monsoon rainfall. J Climate 15:722-744. 
Meehl GA, Arblaster JM, Loschnigg J (2003) Coupled Ocean-Atmosphere Dynamical Processes in the Tropical Indian and Pacific Oceans and the TBO. J. Climate 16:2138-2158.

Nicholls N (1995) All-India summer monsoon rainfall and sea surface temperatures around northern Australia and Indonesia. J Climate 8:1463-1467.

Nitta T, Yamada S (1989) Recent warming of tropical sea surface temperature and its relationship to the Northern Hemisphere circulation. J Meteor Soc Jpn 67:375-383.

Park H-S, Chiang JCH, Lintner BR, Zhang JG (2010) The delayed effect of major El Niño events on Indian monsoon rainfall. J Climate 23:932-946.

Parthasarathy B, Munot AA, Kothawale DR (1995) All India monthly and seasonal rainfall series: 1871-1993. Theor Appl Climatol 49:217-224.

Peings Y, Douville H, Terray P (2009) Extended winter Pacific North America oscillation as a precursor of the Indian summer monsoon rainfall. Geophys Res Lett 36:L11710. Doi: 10.1029/2009GL038453.

Rajeevan M, Pai DS, Anil Kumar R, Lal B (2006) New statistical models for long-range forecasting of southwest monsoon rainfall over India. Climate Dyn. Doi.10.1007/s00382006-0197-6.

Rajeevan M, Pai D.S (2007) On the El Niño-Indian monsoon predictive relationships. Geophys Res Lett 34:L04704. Doi: 10.1029/2006GL028916.

Rajeevan M, Sridhar L (2008) Inter-annual relationship between Atlantic sea surface temperature anomalies and Indian summer monsoon. Geophys Res Lett 35:L21704. Doi: 10.1029/2008GL036025.

Rasmusson EM, Carpenter TH (1983) The relationship between the eastern Pacific sea surface temperature and rainfall over India and Sri Lanka. Mon Weather Rev 111:517-528. 
Ratnam JV, Behera SK, Masumoto Y, Takajashi K, Yamagata T (2010) Pacific Ocean Origin for the 2009 Indian Summer Monsoon Failure. Geophys Res Lett 37:L07807. Doi:10.1029/2010GL042798.

Rayner NA, Parker DE, Horton EB, Folland CK, Alexander LV, Rowell DP, Kent EC, Kaplan A (2003) Global analyses of sea surface temperature, sea ice, and night marine air temperature since the late nineteenth century. J Geophys Res 108(D14)4407. Doi: 10.1029/2002JD002670

Saji NH, Goswami BN, Vinayachandran PN, Yamagata TA (1999) Dipole Mode in the Tropical Indian Ocean. Nature 401:360-363.

Shukla J, Paolino DA (1983) The Southern Oscillation and long-range forecasting of the summer monsoon rainfall over India. Mon. Wea. Rev. 111:1830-1837.

Shukla J (1987) Interannual variability of monsoons in Monsoons, J.S. Fein et P.L. Stephens, Eds., Wiley, 399-464.

Slingo JM, Annamalai H (2000) 1997 : The El Niño of the century and the response of the Indian summer monsoon. Mon. Wea. Rev. 128:1778-1797.

Sooraj KP, Kug J-S, Li Y, Kang I-S (2009) Impact of El Nino onset timing on the Indian Ocean: Pacific coupling and subsequent El Nino evolution. Theoretical and Applied Climatology 97:1-2, 17-27.

Srivastava AK, Rajeevan M, Kulkarni R (2002) Teleconnection of OLR and SST anomalies over Atlantic Ocean with Indian summer monsoon. Geophys Res Lett $29: 1284$. Doi :10.1029/2001GL013837.

Terray P (1994) An evaluation of climatological data in the Indian Ocean area. J. Meteor. Soc. Japan. 72:359-386.

Terray P, Delecluse P, Labattu S, Terray L (2003) Sea Surface Temperature Associations with the Late Indian Summer Monsoon. Clim Dynam 21:593-618. 
Terray P, Dominiak S (2005) Indian Ocean Sea Surface Temperature and El Niño-Southern Oscillation: a new perspective. J Climate 18:1351-1368.

Terray P, Dominiak S, Delecluse P (2005) Role of the southern Indian Ocean in the transitions of the monsoon-ENSO system during recent decades. Clim Dynam 24:169-195. Doi: 10.1007/s00382-004-0480-3.

Terray P, Chauvin F, Douville H (2007) Impact of southeast Indian Ocean Sea Surface Temperature anomalies on monsoon-ENSO-dipole variability in a coupled ocean-atmosphere model. Clim Dynam 28:553-580. Doi:10.1007/s00382-006-0192-y.

Terray P (2010) Southern Hemisphere extra-tropical forcing: a new paradigm for El NiñoSouthern Oscillation. Clim Dynam. Doi:10.1007/s00382-010-0825-z.

Trenberth KE, Caron JM, Stepaniak DP, Worley S (2002) The evolution of ENSO and global atmospheric surface temperatures. J Geophys Res 107(D8). Doi:10.1029/2000JD000298.

Vimont DJ, Wallace JM, Battisti DS (2003) The seasonal footprinting mechanism in the Pacific: implications for ENSO. J Climate 16:2668-2675.

Vimont DJ, Alexander M, Fontaine A (2009) Midlatitude excitation of tropical variability in the pacific: the role of thermodynamic coupling and seasonality. J Climate 22:518-534.

Walker GT (1924) Correlation in seasonal variations of weather, IV: a further study of world weather. Mem. Ind. Meteorol. Dep.. 24, 275-332.

Wang B (1995) Interdecadal changes in El Niño onset in the last four decades. J Climate $8: 267-285$.

Wang B, An S-I (2002) A mechanism for decadal changes of ENSO behavior: Roles of background wind changes. Climate Dyn. 18:475-486.

Wang B (2006) The Asian Monsoon. Springer- Verlag/Praxis Publishing, New York, 787 pp. 
Wang B, Yang J, Zhou T (2008) Interdecadal Changes in the Major Modes of AsianAustralian Monsoon Variability: Strengthening Relationship with ENSO since the Late 1970s. J. Climate 21:1771-1788.

Webster PJ, Yang S (1992) Monsoon and ENSO: Selectively interactive systems. Quart J Roy Meteor Soc 118:877-926.

Webster PJ, Magana VO, Palmer TN, Shukla J, Tomas RA, Yanai M, Yasunari T (1998) Monsoons: Processes, predictability and the prospects for prediction. J Geophys Res 103(C7):14 451-14 510.

Webster PJ, Hoyos C (2010) Beyond the spring barrier? Nature Geoscience 3:152-153. Doi: 10.1038/ngeo760.

Yang J, Liu Q, Xie S-P, Liu Z, Wu L (2007) Impact of the Indian Ocean SST basin mode on the Asian summer monsoon. Geophys Res Lett 34:L02708. Doi: 10.1029/2006GL028571.

Yoo SH, Fasullo J, Yang S, Ho CH (2010) On the relationship between Indian Ocean sea surface temperature and the transition from El Niño to La Niña. J Geophys Res 115:D15114. Doi:10.1029/2009JD012978.

Zheng X-T, Xie S, Vecchi AG, Liu Q, Hafner J (2010) Indian Ocean dipole response to global warming: Analysis of ocean-atmospheric feedbacks in a coupled model. J Climate 23(5). Doi : 10.1175/2009JCLI3326.1

\section{Figure captions:}


Figure 1: Standardized time series of ISM rainfall in JJAS (blue curve), IOD in SON (green curve) and Niño3.4 in DJ (red curve) during 1950-2006. The one standard deviation line (in black) is also added to this figure as it helps identify the extreme years.

Figure 2: Standardized time series of ISM rainfall in JJAS (blue curve), JJ (green curve) and AS (red curve) superimposed with the standardized Niño3.4 time series in JJAS (black dotted curve) during (a) 1950-1976 and (b) 1979-2006. The one standard deviation line (in black) is also added to this figure as it helps identify the extreme years.

Figure 3: Global correlation between ISM rainfall in JJ and bimonthly SST anomalies from the boreal fall preceding $\left(\mathrm{ON}^{-1}\right)$ to that following (ON) the ISM season during (a) 1950-1976 and (b) 1979-2006 time periods. Correlation coefficients that are above the $90 \%$ confidence level estimated with a phase-scrambling bootstrap test with 999 samples are encircled.

Figure 4: Global correlation between ISM rainfall in JJ and bimonthly SLP anomalies from the boreal fall preceding $\left(\mathrm{ON}^{-1}\right)$ to that following (ON) the ISM season during (a) 1950-1976 and (b) 1979-2006 time periods. Correlation coefficients that are above the $90 \%$ confidence level estimated with a phase-scrambling bootstrap test with 999 samples are encircled.

Figure 5: Global correlation between ISM rainfall in AS and bimonthly SST anomalies from the boreal fall preceding $\left(\mathrm{ON}^{-1}\right)$ to that following (ON) the ISM season during (a) 1950-1976 and (b) 1979-2006 time periods. Correlation coefficients that are above the $90 \%$ confidence level estimated with a phase-scrambling bootstrap test with 999 samples are encircled.

Figure 6: Global correlation between ISM rainfall in AS and bimonthly SLP anomalies from the boreal fall preceding $\left(\mathrm{ON}^{-1}\right)$ to that following (ON) the ISM season during (a) 1950-1976 and (b) 1979-2006 time periods. Correlation coefficients that are above the $90 \%$ confidence level estimated with a phase-scrambling bootstrap test with 999 samples are encircled.

Figure 7: Composite SST (top panels) and SLP (bottom panels) anomalies in JJ and AS during (a) the 16 El Niño years (in 1951, 1957, 1963, 1965, 1968, 1969, 1972, 1976, 1977, 1982, 1986, 1987, 1991, 1994, 1997 and 2002) and (b) 18 La Niña years (in 1950, 1954, 1955, 1964, 1966, 1967, 1970, 1973, 1975, 1983, 1984, 1985, 1988, 1995, 1998, 1999, 2000 and 2005). The composite anomalies significant at the $90 \%$ confidence level are encircled. 
The statistical significance has been determined by the method outlined in Terray et al. (2003).

Figure 8: Correlation of summer SST (top panels) and SLP anomalies (bottom panels) with (a) ISM rainfall in JJ and (b) ISM rainfall in AS, during the 16 El Niño years (in 1951, 1957, 1963, 1965, 1968, 1969, 1972, 1976, 1977, 1982, 1986, 1987, 1991, 1994, 1997 and 2002). Correlations significant at the the $90 \%$ confidence level according to a two-tailed student't test are encircled.

Figure 9: Correlation of summer SST (top panels) and SLP anomalies (bottom panels) with (a) ISM rainfall in JJ and (b) ISM rainfall in AS, during the 18 La Niña years (in 1950, 1954, 1955, 1964, 1966, 1967, 1970, 1973, 1975, 1983, 1984, 1985, 1988, 1995, 1998, 1999, 2000 and 2005). Correlations significant at the the 90\% confidence level according to a two-tailed student't test are encircled. 


\section{Table captions:}

Table 1: Description of the different indices used in this study as well as their first references in the literature. Note that these key indices are computed from the detrended SST dataset separately over each time period (1950-1976 and 1979-2006).

Table 2: Cross-correlations between the key SST indices (defined in Table 1) and the ISM rainfall (ISMR) averaged in seasonal (JJAS) and bimonthly mean (JJ and AS), for both the 1950-1976 (blue values) and 1979-2006 (red values) time periods. The coefficients exceeding the $10 \%, 5 \%$ and $5 \%$ confidence levels according to the phase-scrambling bootstrap test of Ebisuzaki (1997) with 999 samples are followed by one asterisks $(*)$, two asterisks (**) and three asterisks $(* * *)$, respectively.

Table 3: Regression between ISM rainfall in JJ, AS and JJAS, and the IOD, IOD-west node and IOD-east node time series in SON during the 16 El Niño years (in 1951, 1957, 1963, 1965, 1968, 1969, 1972, 1976, 1977, 1982, 1986, 1987, 1991, 1994, 1997 and 2002). Regression coefficient are given in $\mathrm{mm} /$ month by standard deviation of the IOD time series. The last line shows the mean composite values (in mm/month) of ISM rainfall in JJ, AS and JJAS during the same El Niño years. 
Figure2

Figure 2

(a)

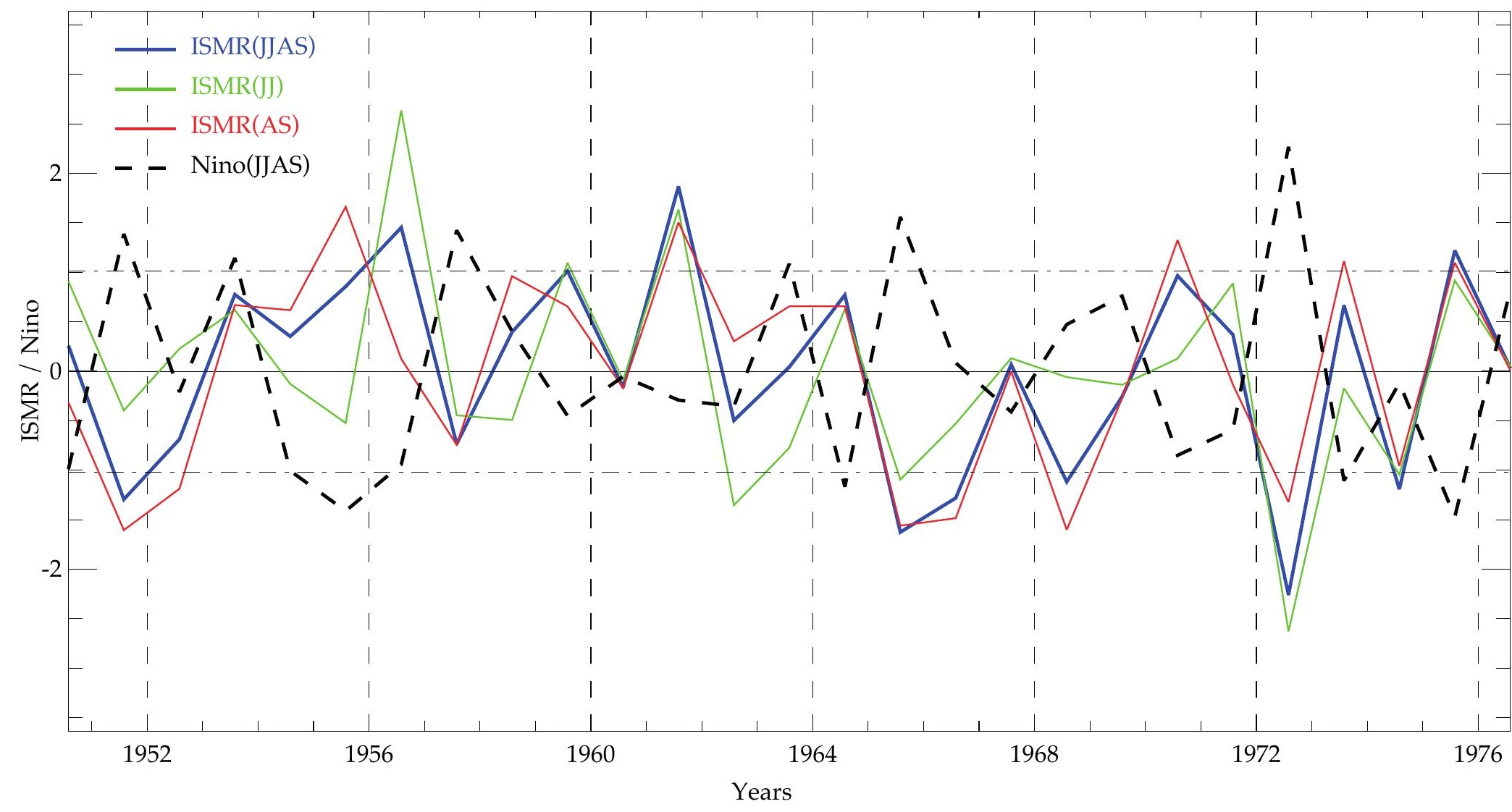

(b)

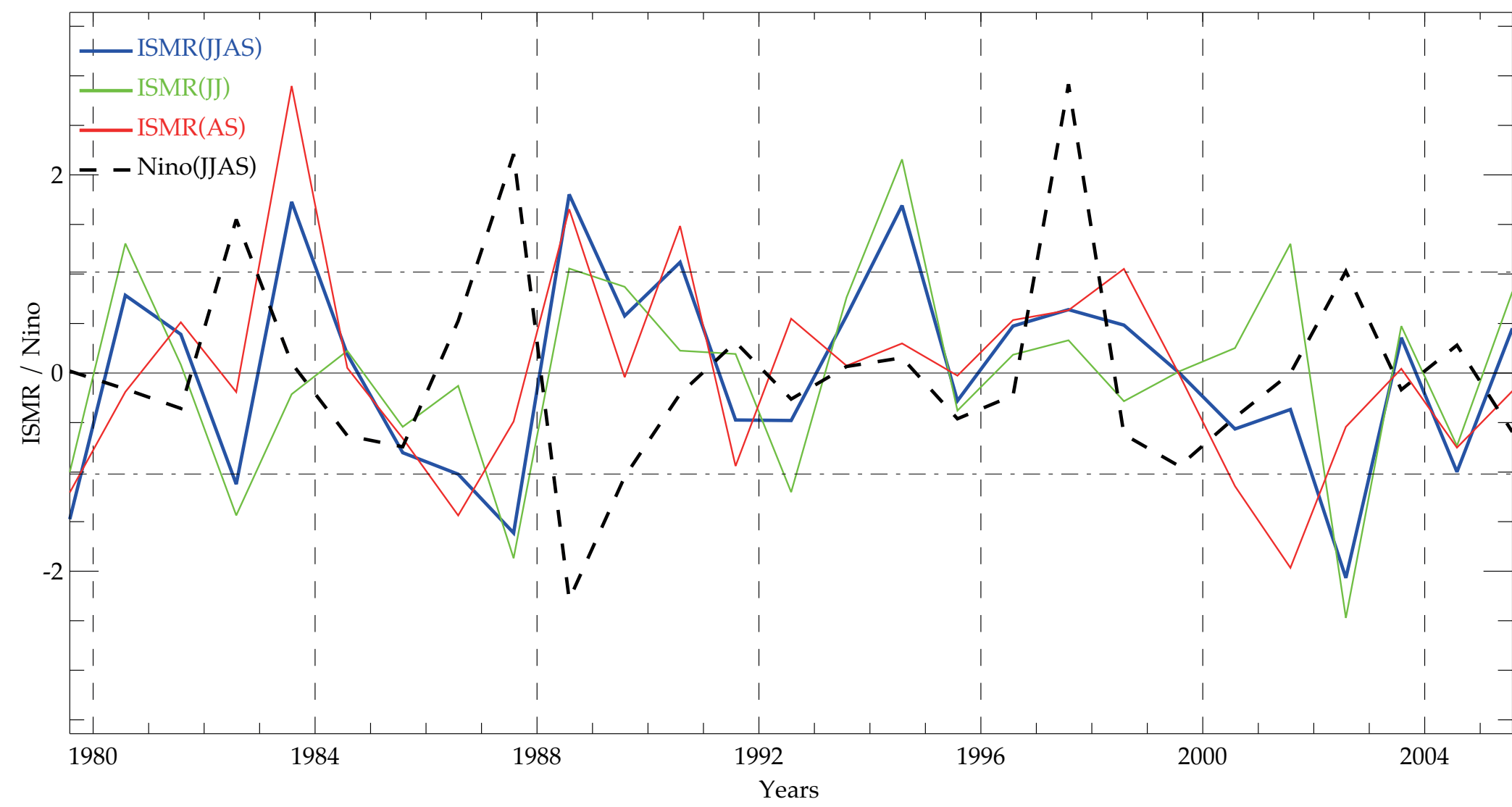


Figure 3

(a) 1950 - 1976
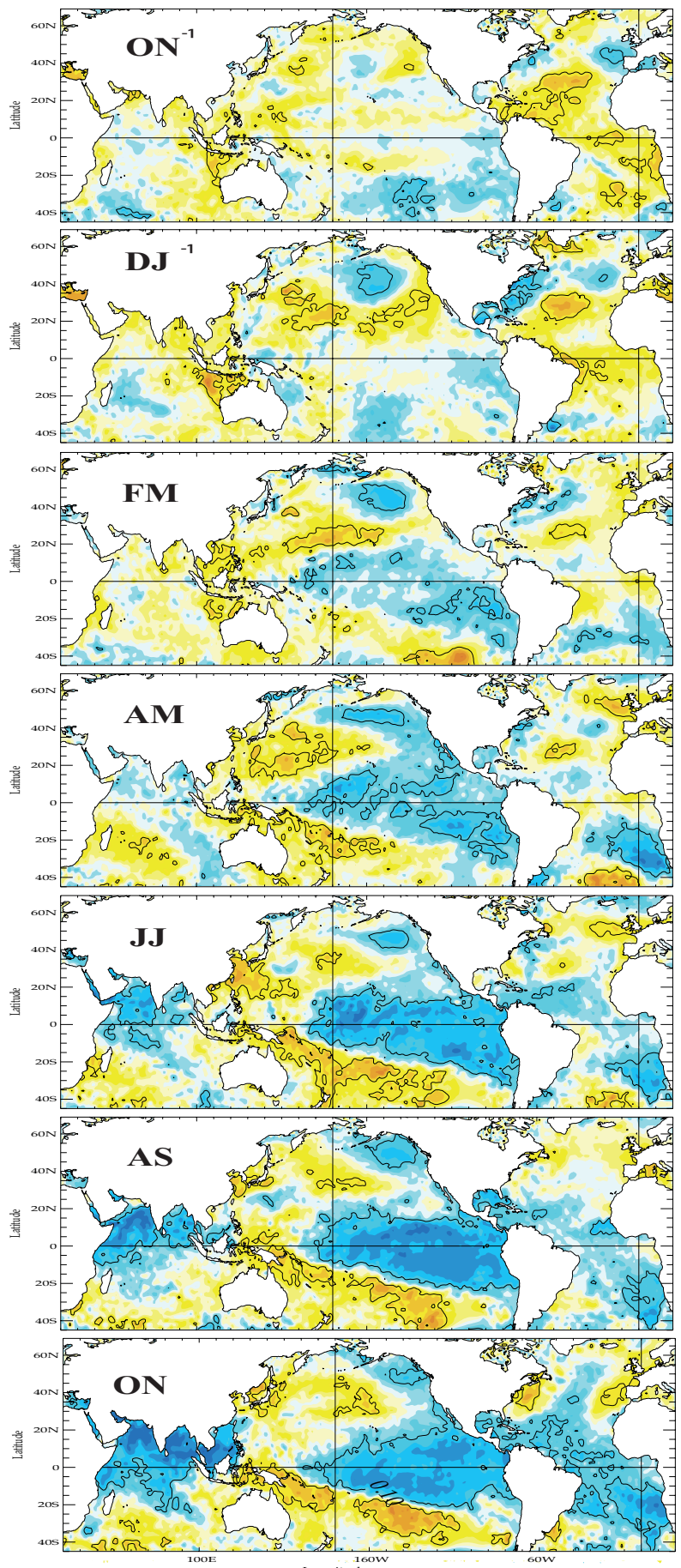

(b) 1979 - 2006

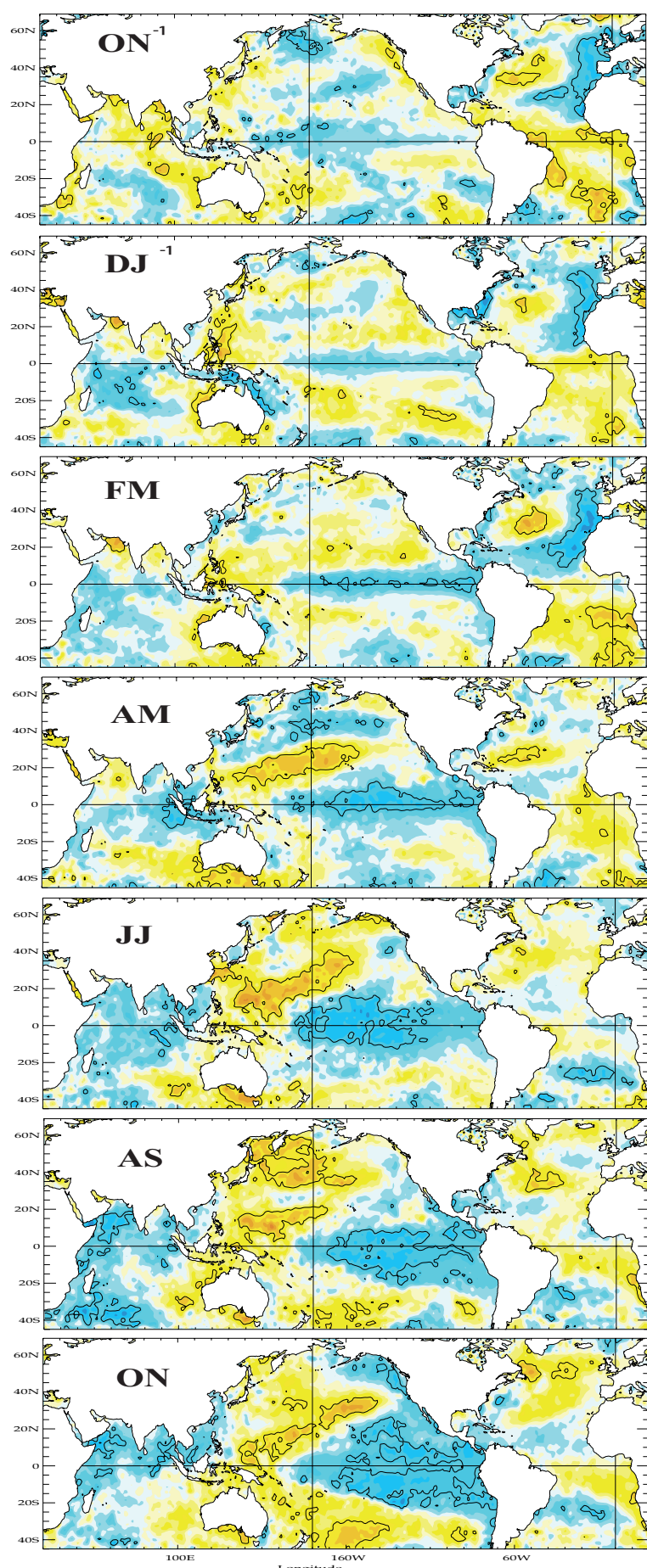


(a) 1950 - 1976 (b) 1979 - 2006
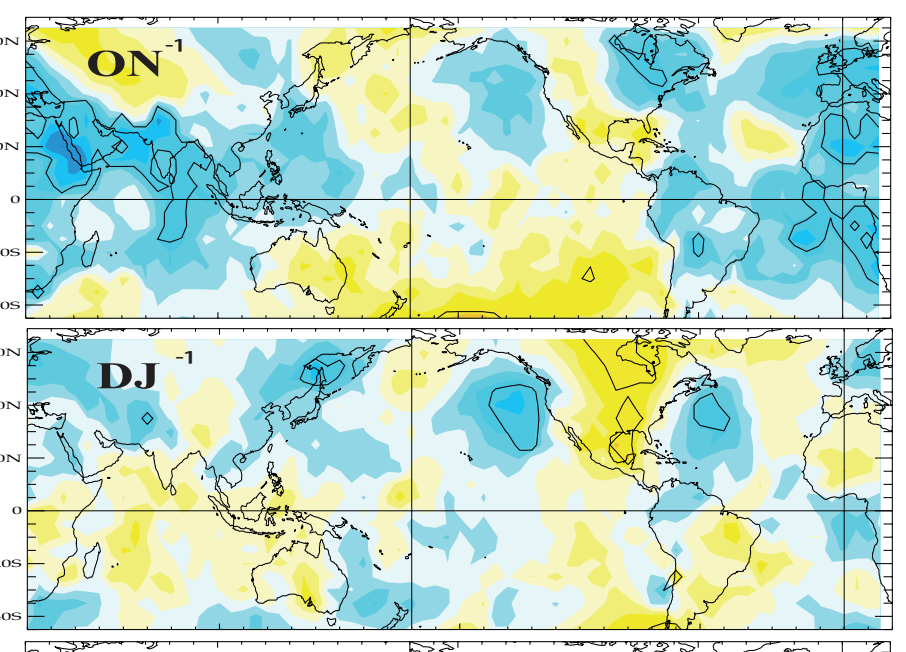

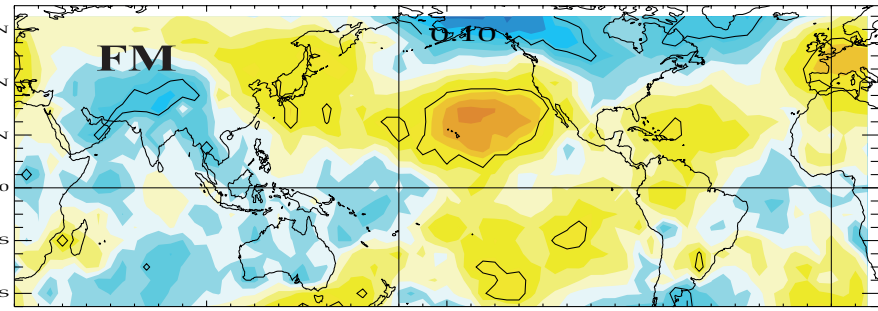
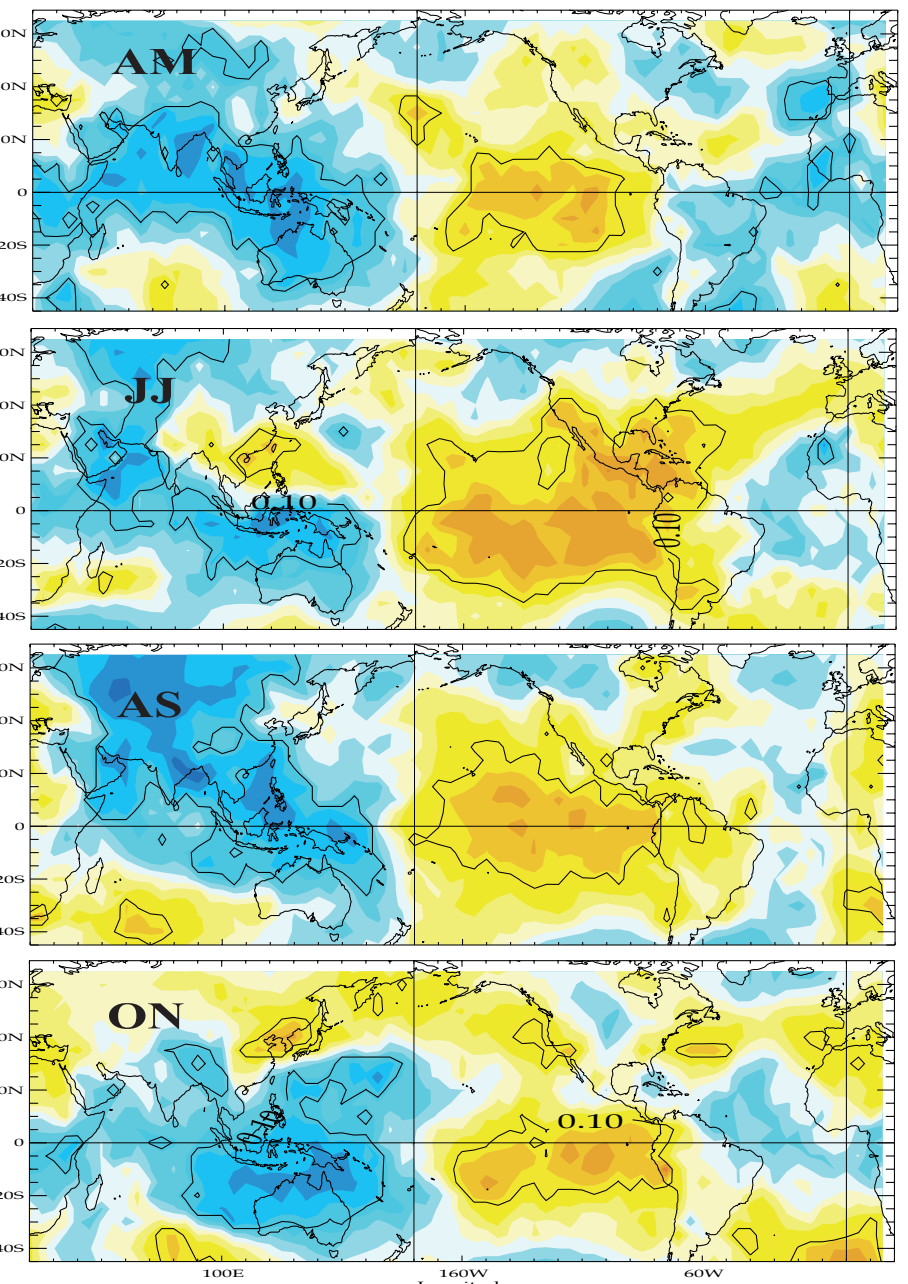
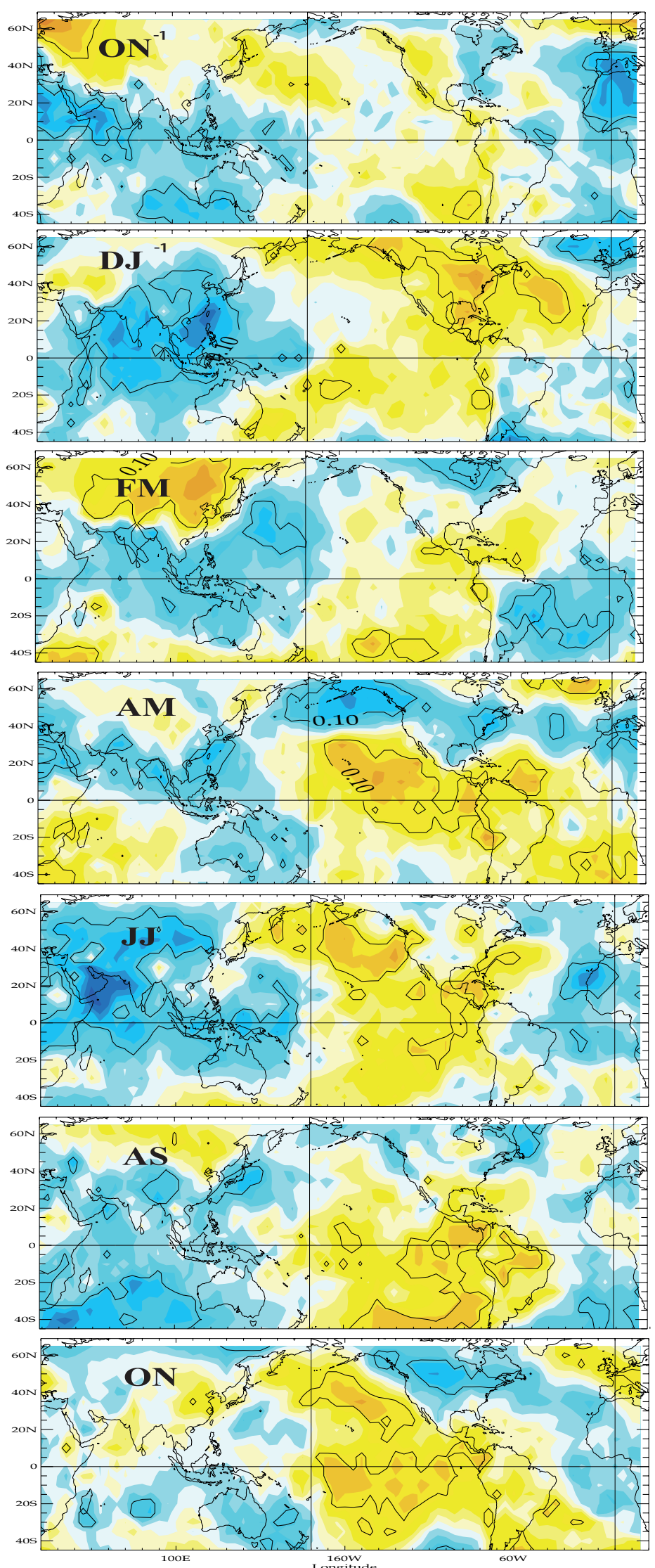
(a) 1950 - 1976 (b) 1979 - 2006

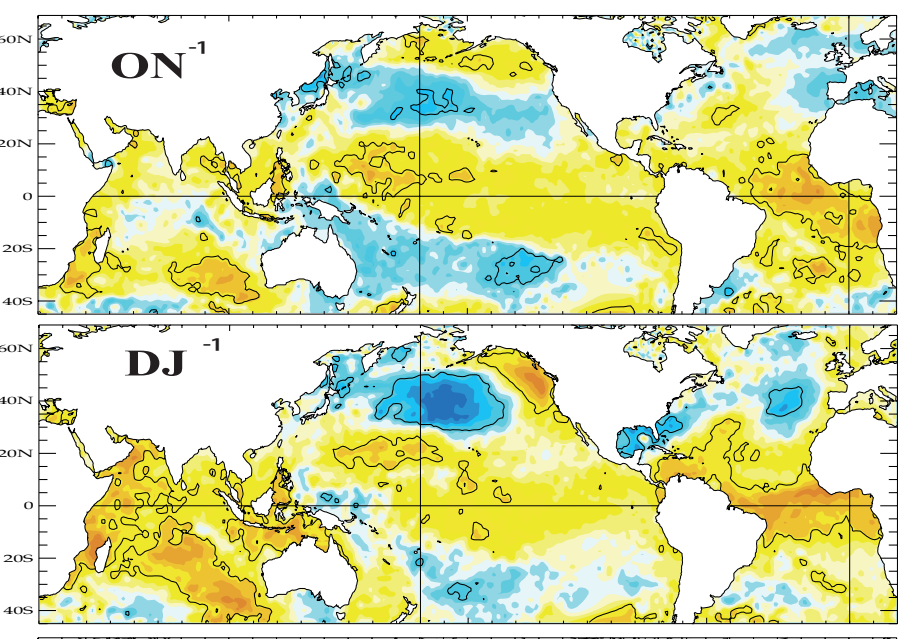

FM F
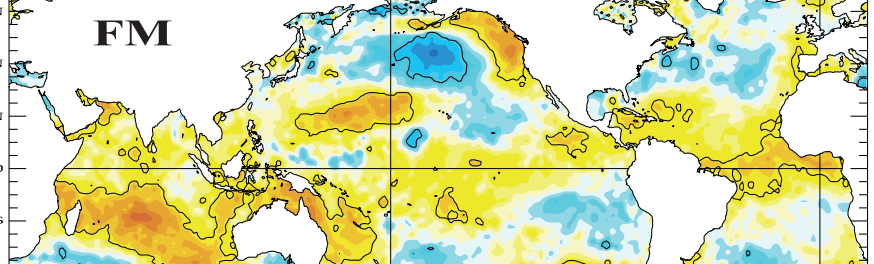

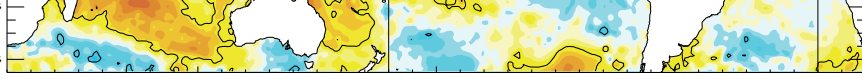

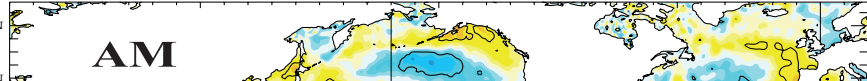

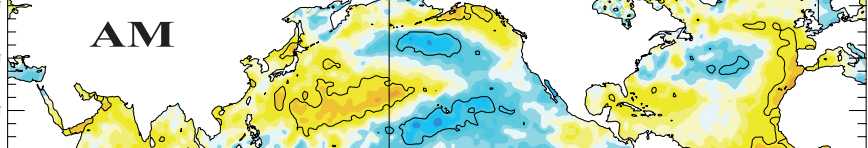

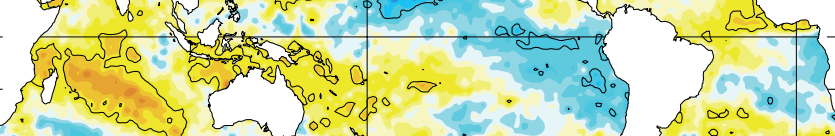

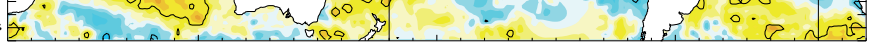
JJ

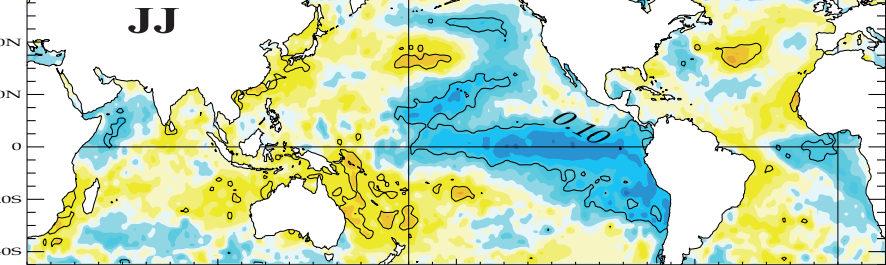

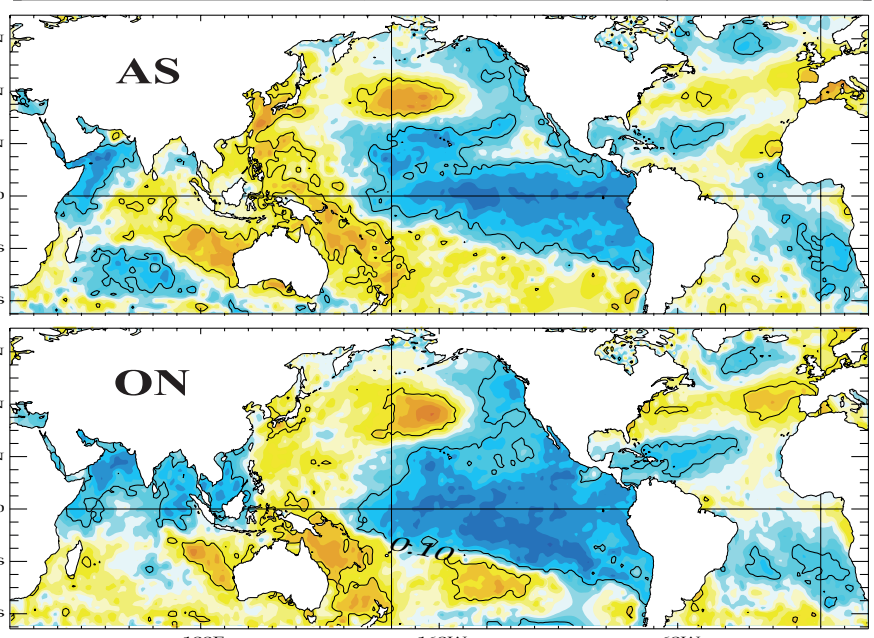
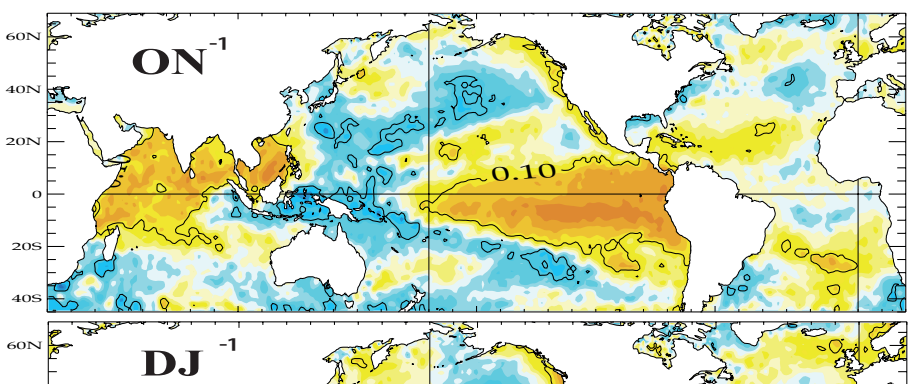
DJ FM FM

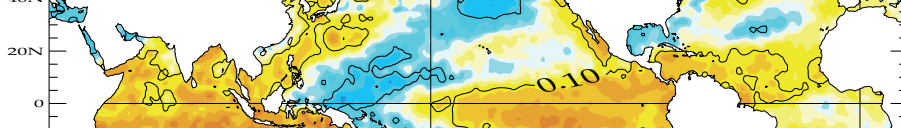

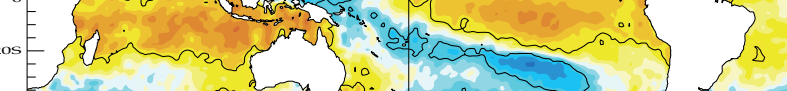

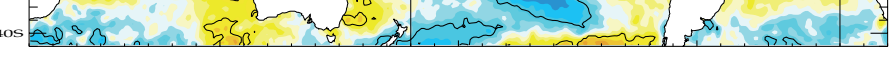
कon AM

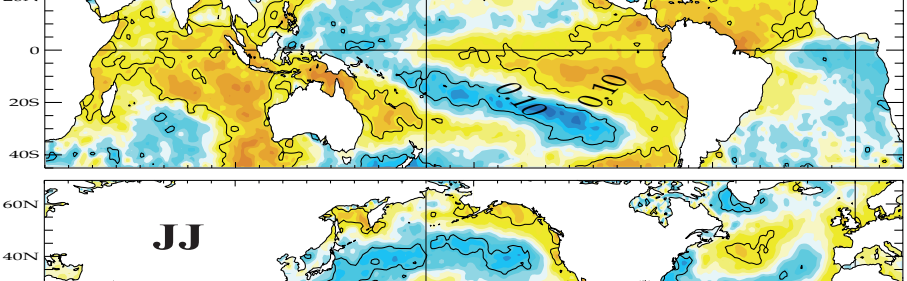
JJ 30,

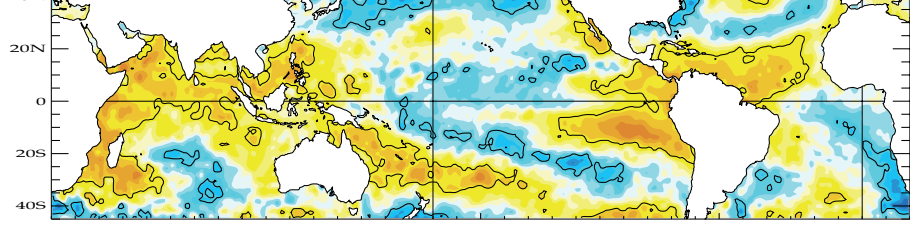
AS ON 
(a) 1950 - 1976
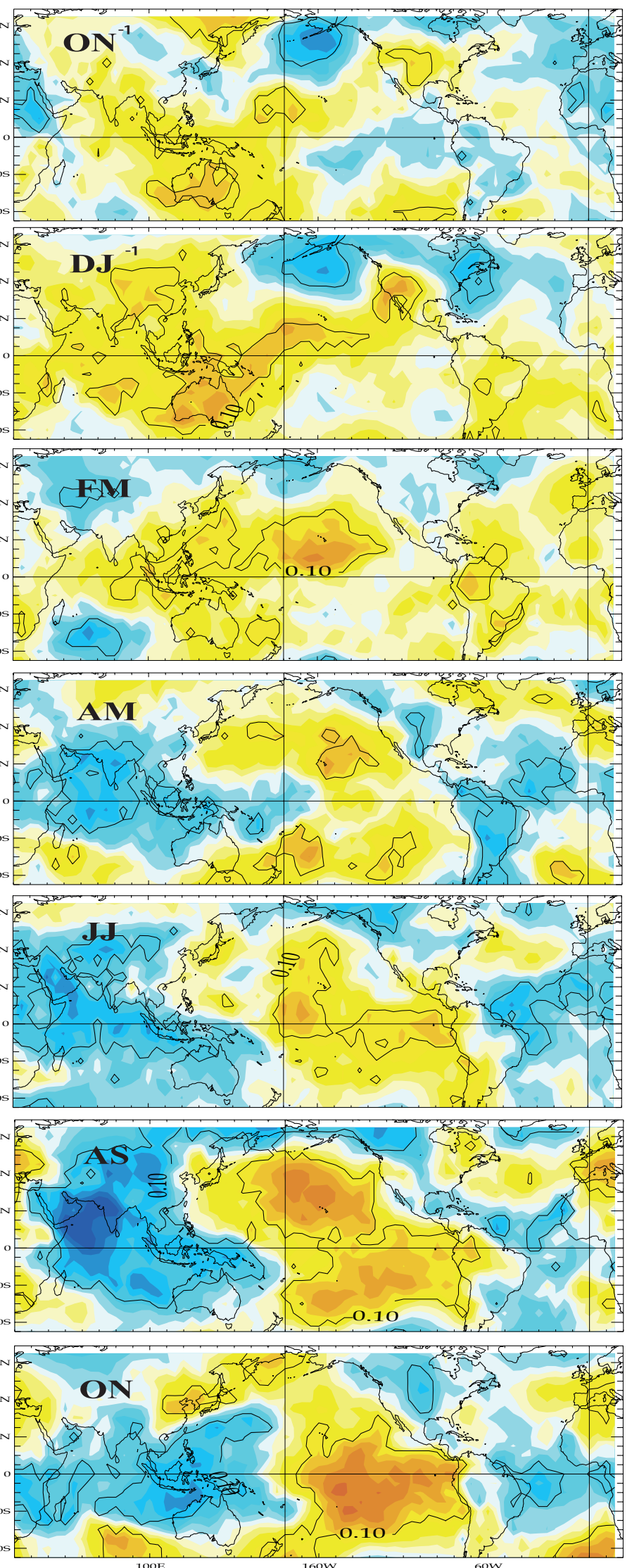

(b) 1979 - 2006
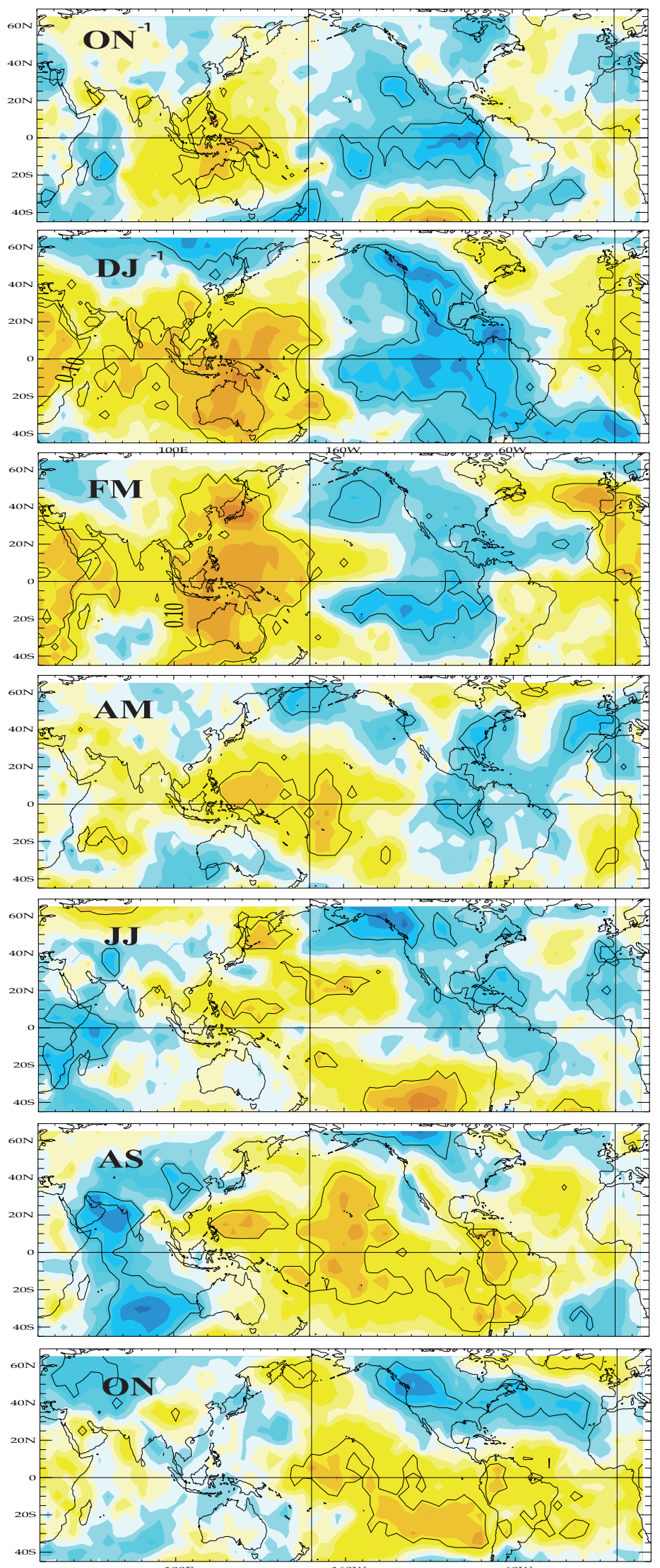


\section{(a) El Nino}
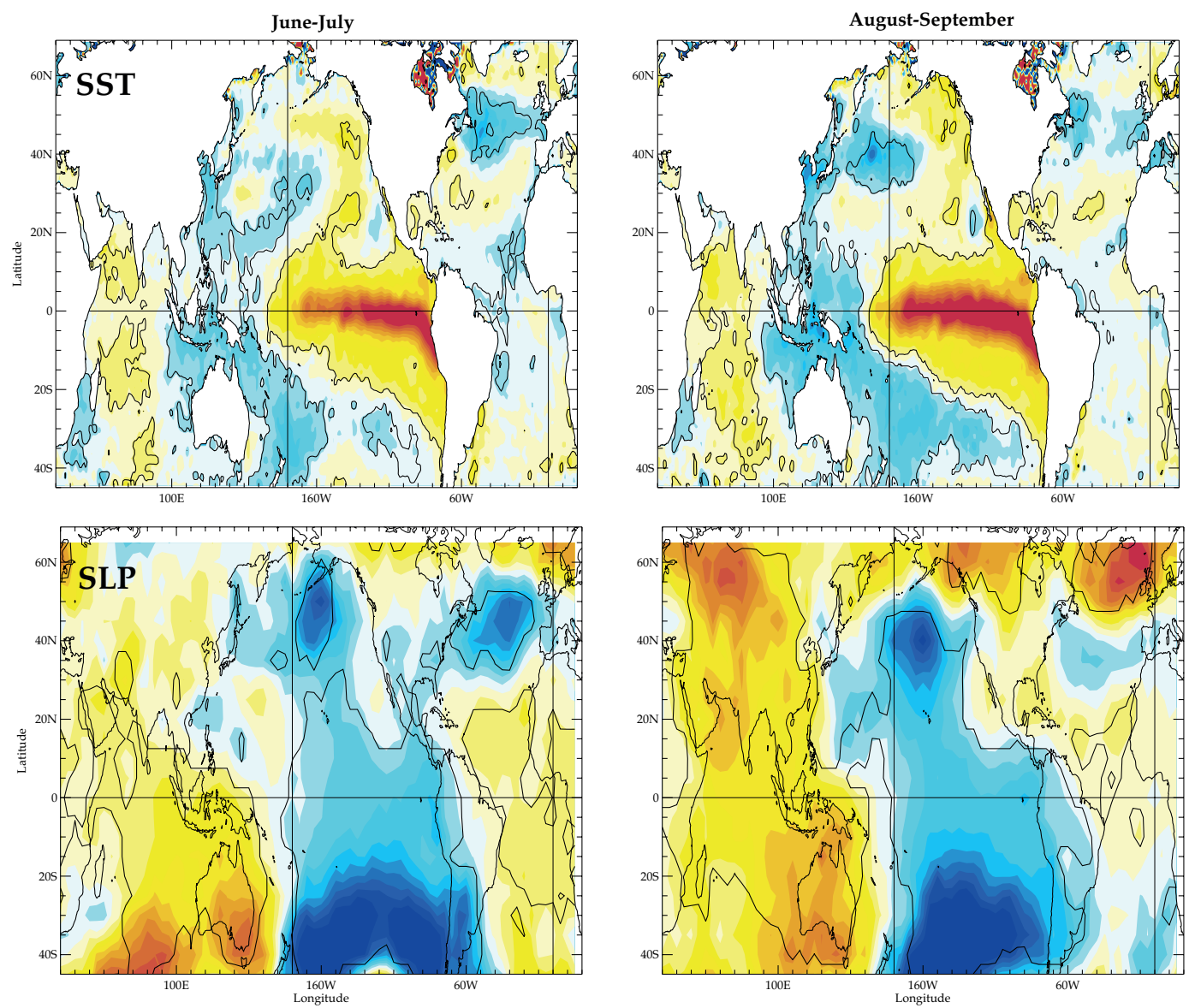

\section{(b) La Nina}
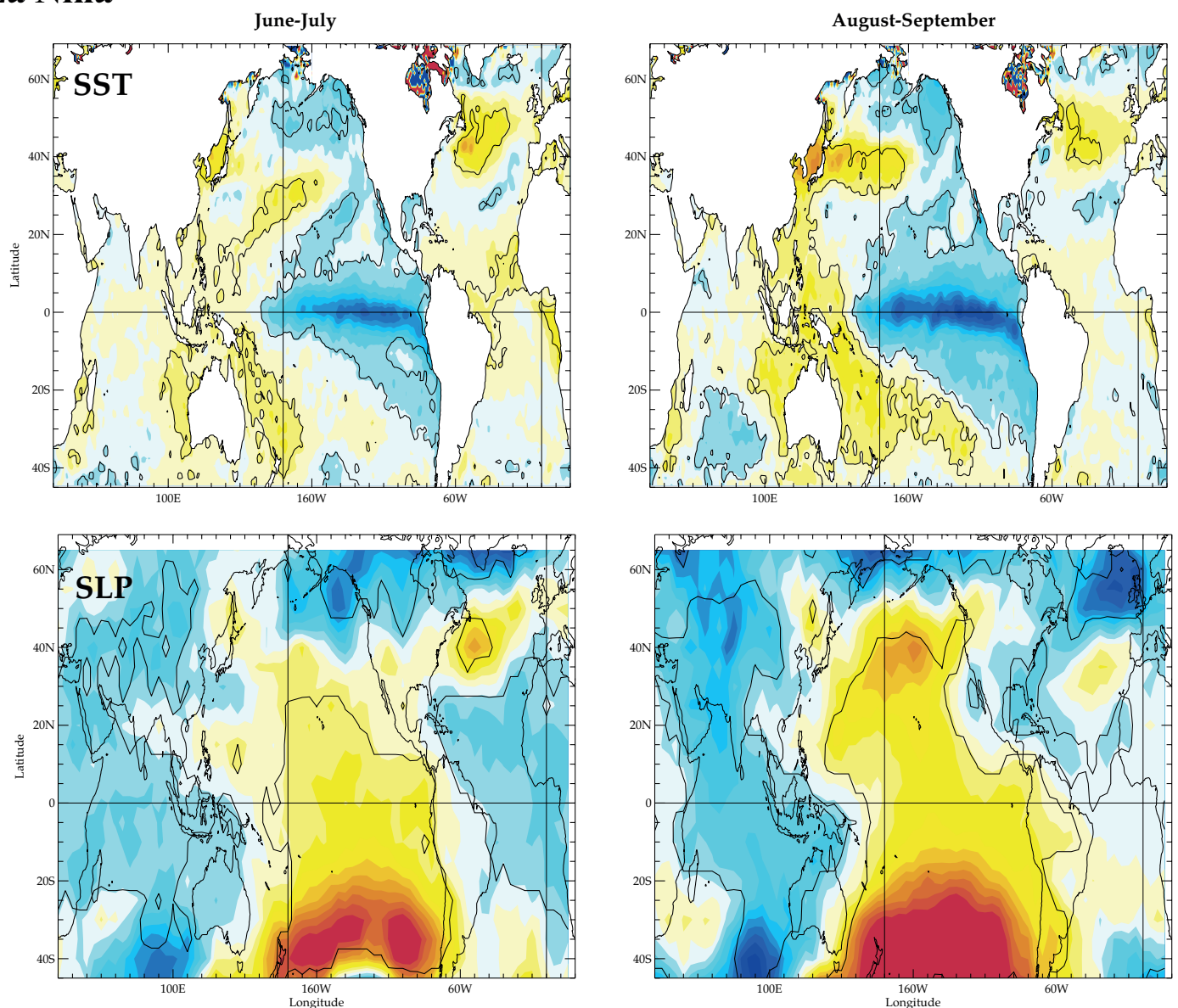
(a) Correlation with ISMR (JJ)
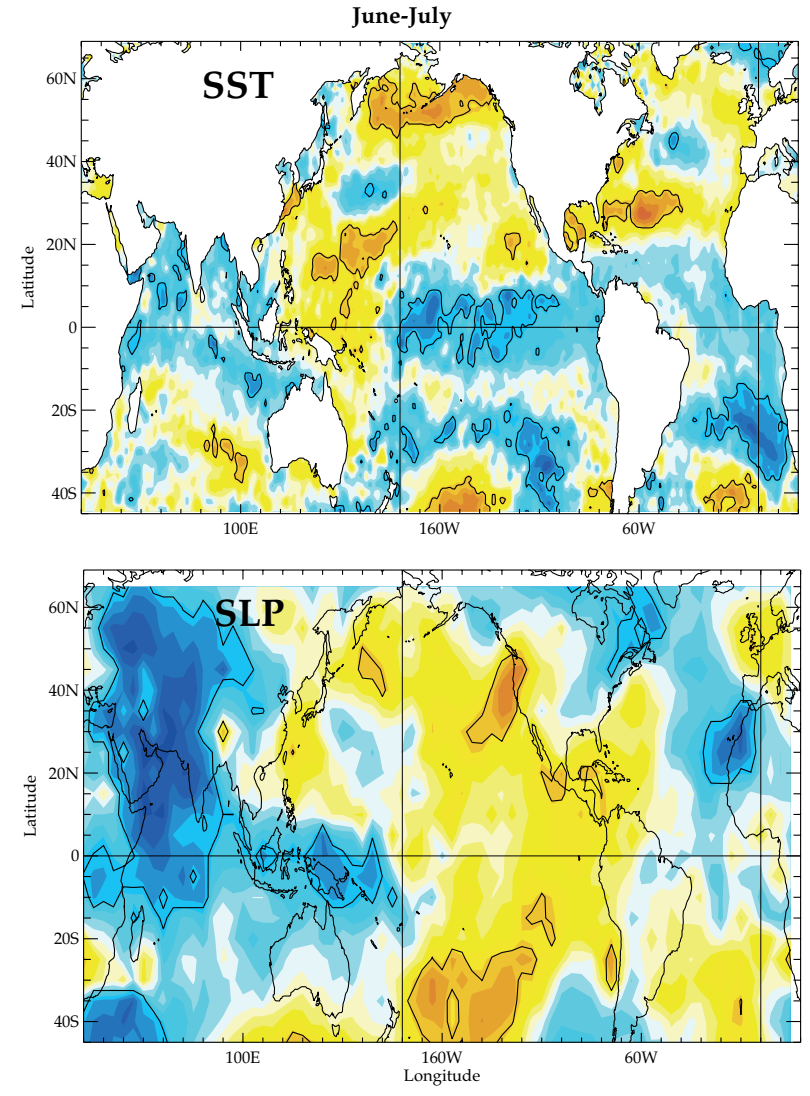

(b) Correlation with ISMR (AS)
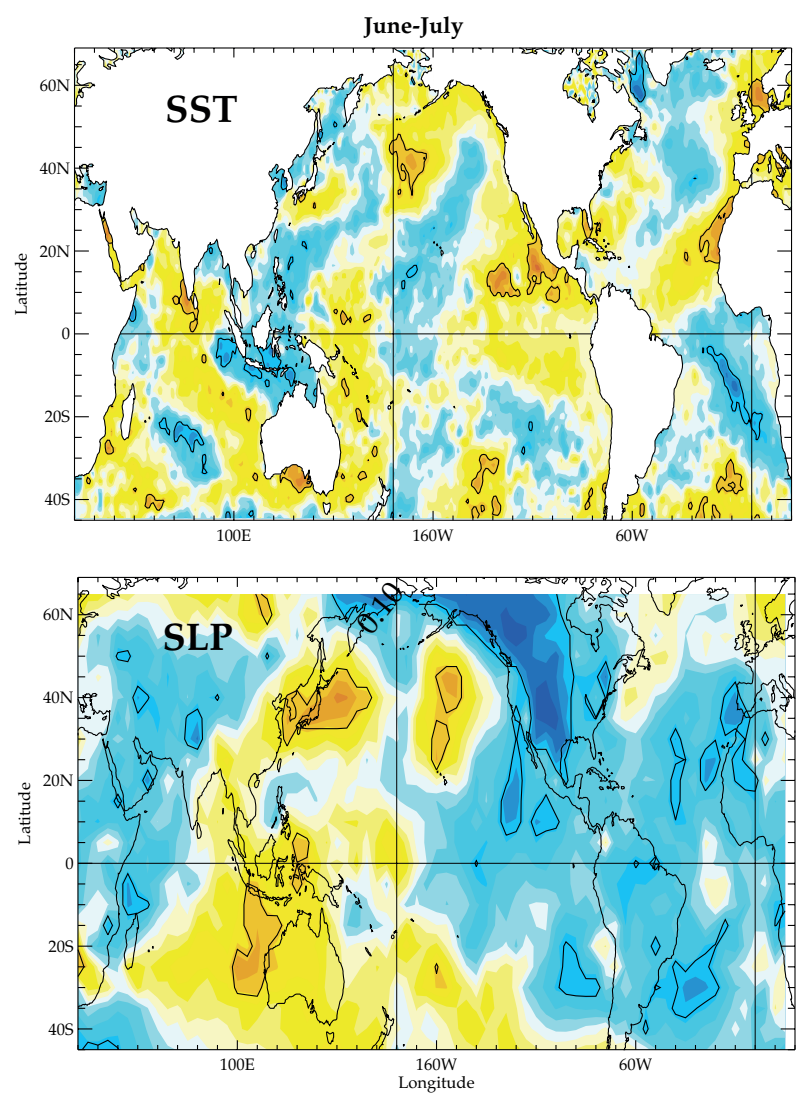
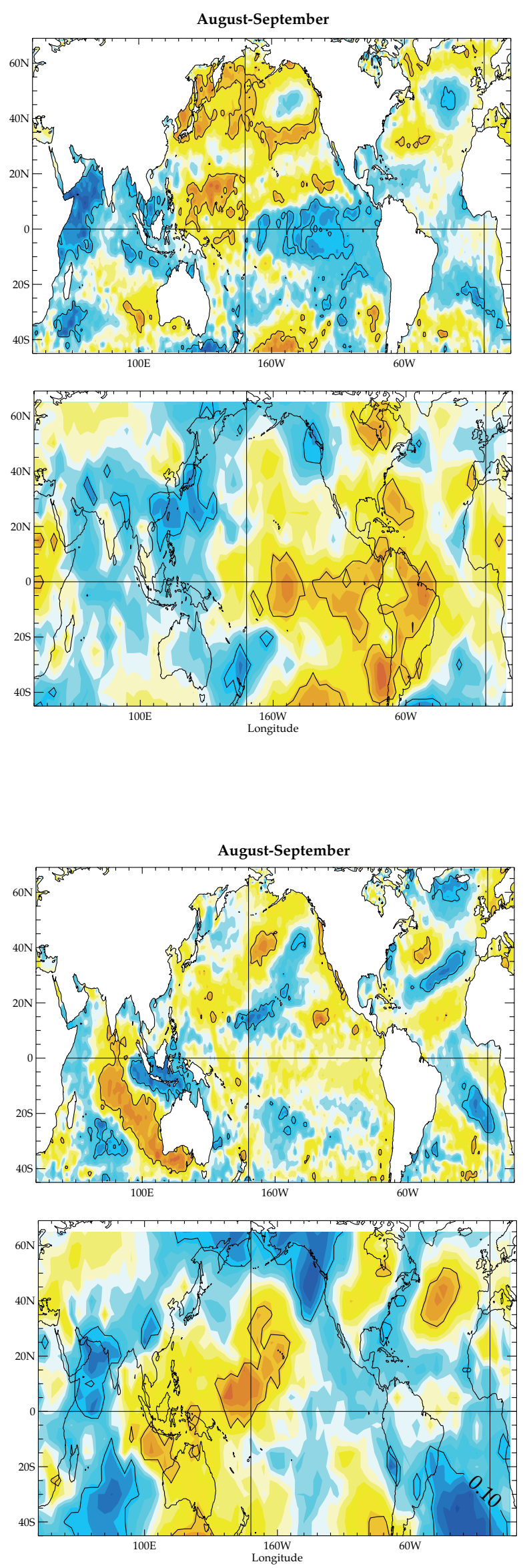

$\begin{array}{lllllllllll}-1.0 & -0.8 & -0.6 & -0.4 & -0.2 & 0.0 & 0.2 & 0.4 & 0.6 & 0.8 & 1.0\end{array}$




\section{(a) Correlation with ISMR (JJ)}
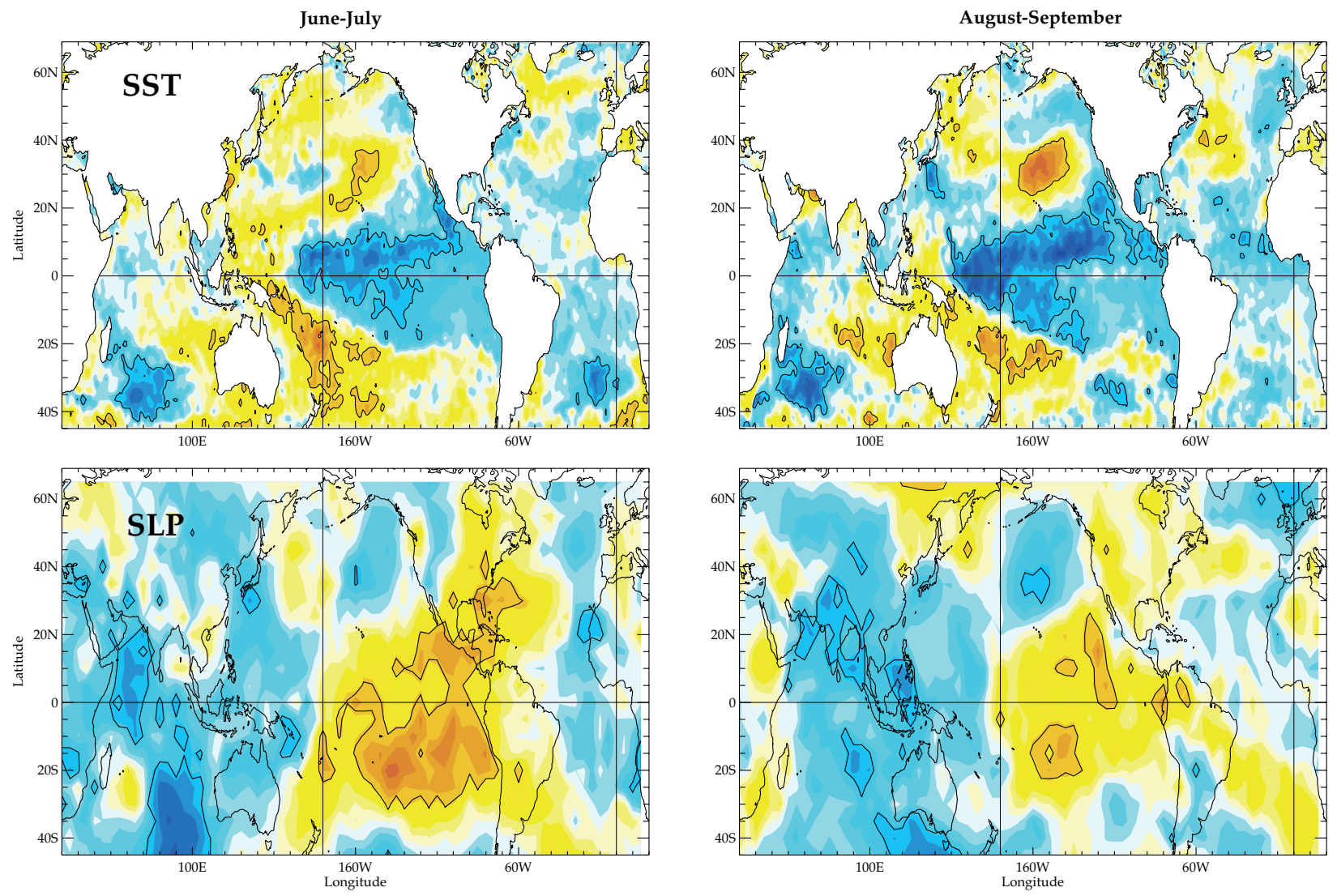

\section{(b) Correlation with ISMR (AS)}
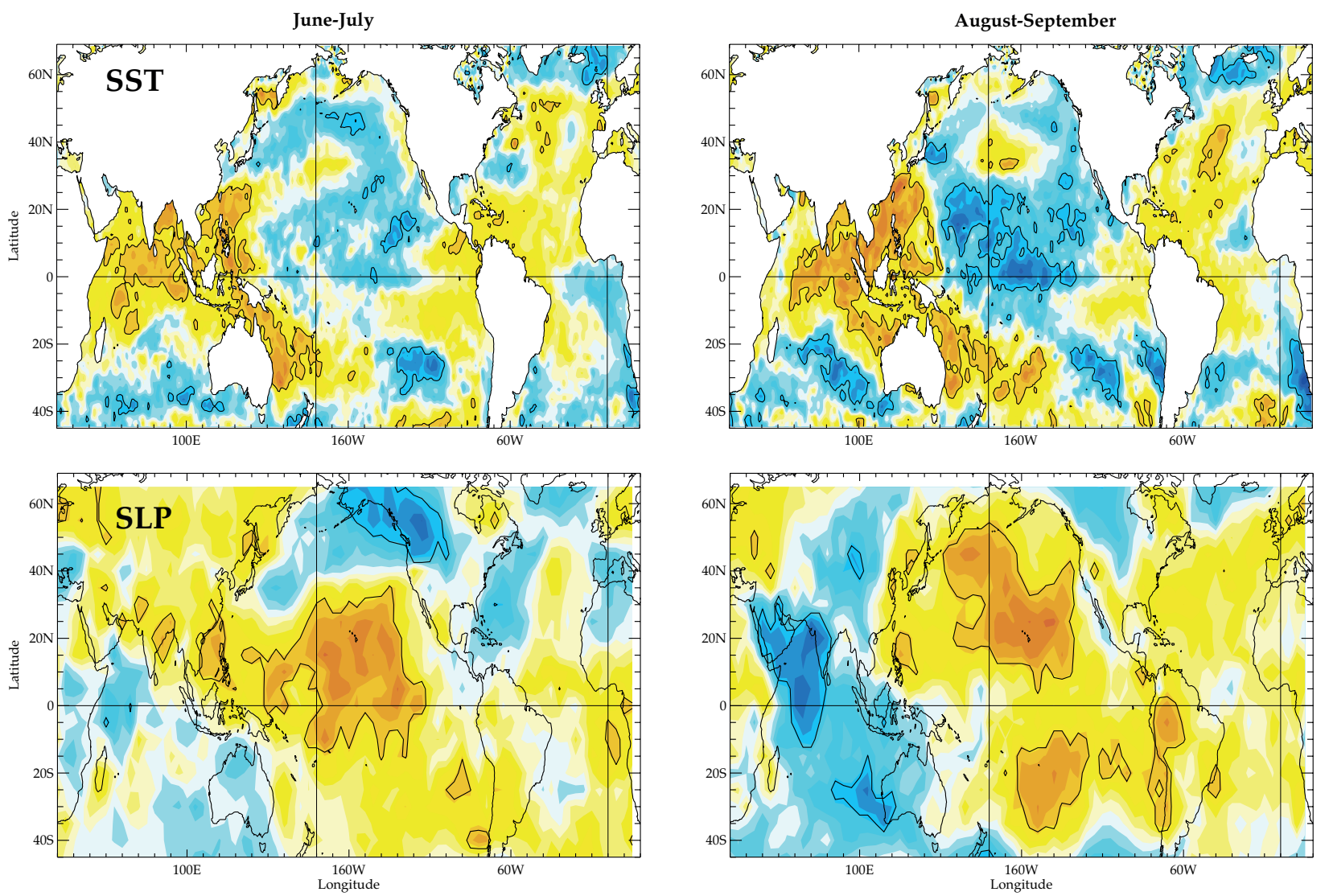
Table 1:

\begin{tabular}{c|c|c|c}
$\begin{array}{c}\text { Index } \\
\text { name }\end{array}$ & Reference & $\begin{array}{c}\text { Geographical } \\
\text { domain }\end{array}$ & Peaking season \\
\hline Nino & Nino3.4 index & $\begin{array}{c}170^{\circ} \mathrm{W}-120^{\circ} \mathrm{W} \\
5^{\circ} \mathrm{N}-5^{\circ} \mathrm{S}\end{array}$ & $\begin{array}{c}\text { December-January } \\
\text { (DJ) }\end{array}$ \\
\hline \multirow{3}{*}{ IOB } & $\begin{array}{c}\text { Indian Ocean Basin Mode } \\
\text { (Yang et al., 2007) }\end{array}$ & $\begin{array}{c}40^{\circ}-110^{\circ} \mathrm{E} \\
20^{\circ} \mathrm{S}-20^{\circ} \mathrm{N}\end{array}$ & $\begin{array}{c}\text { April-May } \\
\text { (AM) }\end{array}$ \\
\hline SEIO & $\begin{array}{c}\text { South East Indian Ocean index } \\
\text { (Terray and Dominiak, 2005) }\end{array}$ & $\begin{array}{c}90^{\circ}-122^{\circ} \mathrm{E} \\
5^{\circ}-45^{\circ} \mathrm{S}\end{array}$ & $\begin{array}{c}\text { February-March } \\
\text { (FM) }\end{array}$ \\
\hline \multirow{2}{*}{ IOD } & $\begin{array}{c}\text { Indian Ocean Dipole Mode } \\
\text { (Saji et al., 1999) }\end{array}$ & $\begin{array}{c}\left(60^{\circ} \mathrm{E}-80^{\circ} \mathrm{E}\right. \\
\left.10^{\circ} \mathrm{N}-10^{\circ} \mathrm{S}\right) \\
- \text { East box } \\
\left(90^{\circ} \mathrm{E}-110^{\circ} \mathrm{E}\right. \\
\left.10^{\circ} \mathrm{S}-0^{\circ} \mathrm{S}\right)\end{array}$ & $\begin{array}{c}\text { September to November } \\
\text { (SON) }\end{array}$ \\
& &
\end{tabular}


Table 2:

\begin{tabular}{|c|c|c||c|c||c|c|}
\cline { 2 - 7 } \multicolumn{1}{c|}{} & \multicolumn{2}{c||}{ ISMR (JJAS) } & \multicolumn{2}{c||}{ ISMR (JJ) } & \multicolumn{2}{c|}{ ISMR (AS) } \\
\hline IOB & 0.24 & 0.19 & -0.01 & -0.15 & $0.36^{*}$ & $0.45^{* *}$ \\
\hline Nino(-1) & 0.20 & 0.18 & -0.03 & -0.20 & 0.32 & $0.50^{* *}$ \\
\hline SEIO & $0.41^{* *}$ & $0.39^{* *}$ & 0.16 & 0.06 & $0.49^{* *}$ & $0.54^{* * *}$ \\
\hline Nino(0) & $-0.64^{* * *}$ & $-0.40^{* *}$ & $-0.47^{* *}$ & -0.30 & $-0.59^{* * *}$ & -0.30 \\
\hline IOD(0) & -0.22 & -0.16 & -0.24 & -0.16 & -0.14 & -0.07 \\
\hline IOD(0)-West box & $-0.45^{* *}$ & -0.18 & $-0.47^{* *}$ & $-0.34^{*}$ & -0.30 & 0.08 \\
\hline IOD(0)-East box & -0.15 & 0.10 & -0.14 & -0.01 & -0.11 & 0.17 \\
\hline IOD(-1) & -0.04 & 0.24 & -0.15 & -0.02 & 0.06 & $0.38^{* *}$ \\
\hline IOD(-1)-West box & 0.12 & $0.37^{*}$ & 0.02 & 0.06 & 0.16 & $0.51^{* *}$ \\
\hline IOD(-1)-East box & 0.19 & -0.07 & 0.27 & 0.07 & 0.08 & -0.17 \\
\hline
\end{tabular}

${ }^{*}: P<0.1 ;{ }^{* *}: P<0.05 ;{ }^{* * *}: P<0.005$ 
Table 3:

\begin{tabular}{|c|c|c|c|}
\hline & ISMR (JJAS) & ISMR (JJ) & ISMR (AS) \\
\hline IOD (SON) & 2.97 & -3.27 & 9.20 \\
\hline IOD - West node (SON) & -8.43 & -17.00 & 0.15 \\
\hline IOD - East node (SON) & -10.83 & -9.75 & -11.90 \\
\hline Composite anomalies & -14.39 & -12.06 & -16.72 \\
\hline
\end{tabular}

